Patrick L. Inácio, Fábio Nogueira, F. Ferreira, C. Vidal, Norbert Schell, Teemu Tero, Pedro Vilaça, J. P. Oliveira, Telmo G. Santos, Functionalized material production via multi-stack Upward Friction Stir Processing (UFSP), Materials and Manufacturing Processes. DOI: https://doi.org/10.1080/10426914.2021.1942909

\title{
Functionalized material production via multi-stack Upward Friction Stir Processing (UFSP)
}

Patrick L. Inácio ${ }^{\mathrm{a}}$, Fábio Nogueira ${ }^{\mathrm{a}}$, Francisco B. Ferreira ${ }^{\mathrm{a}}$, C. Vidal $^{\mathrm{a}}$, Norbert Schell ${ }^{\mathrm{b}}$, Teemu Tero $^{c}$, Pedro Vilaça ${ }^{c}$, J. P. Oliveira ${ }^{a}$, Telmo G. Santos ${ }^{a}$.

a UNIDEMI, Department of Mechanical and Industrial Engineering, NOVA School of Science and Technology, NOVA University Lisbon, 2829-516 Caparica, Portugal.

b Helmholtz-Zentrum Geesthacht, Institute of Materials Research, Max-Planck-Str. 1, Geesthacht, 21502, Germany.

c Department of Mechanical Engineering, School of Engineering, Aalto University, 02150 Espoo, Finland.

${ }^{*}$ Corresponding author:

E-mail address: p.inacio@ campus.fct.unl.pt (Patrick L. Inácio); telmo.santos@ @ft.unl.pt (Telmo G. Santos)

\section{Graphical Abstract}

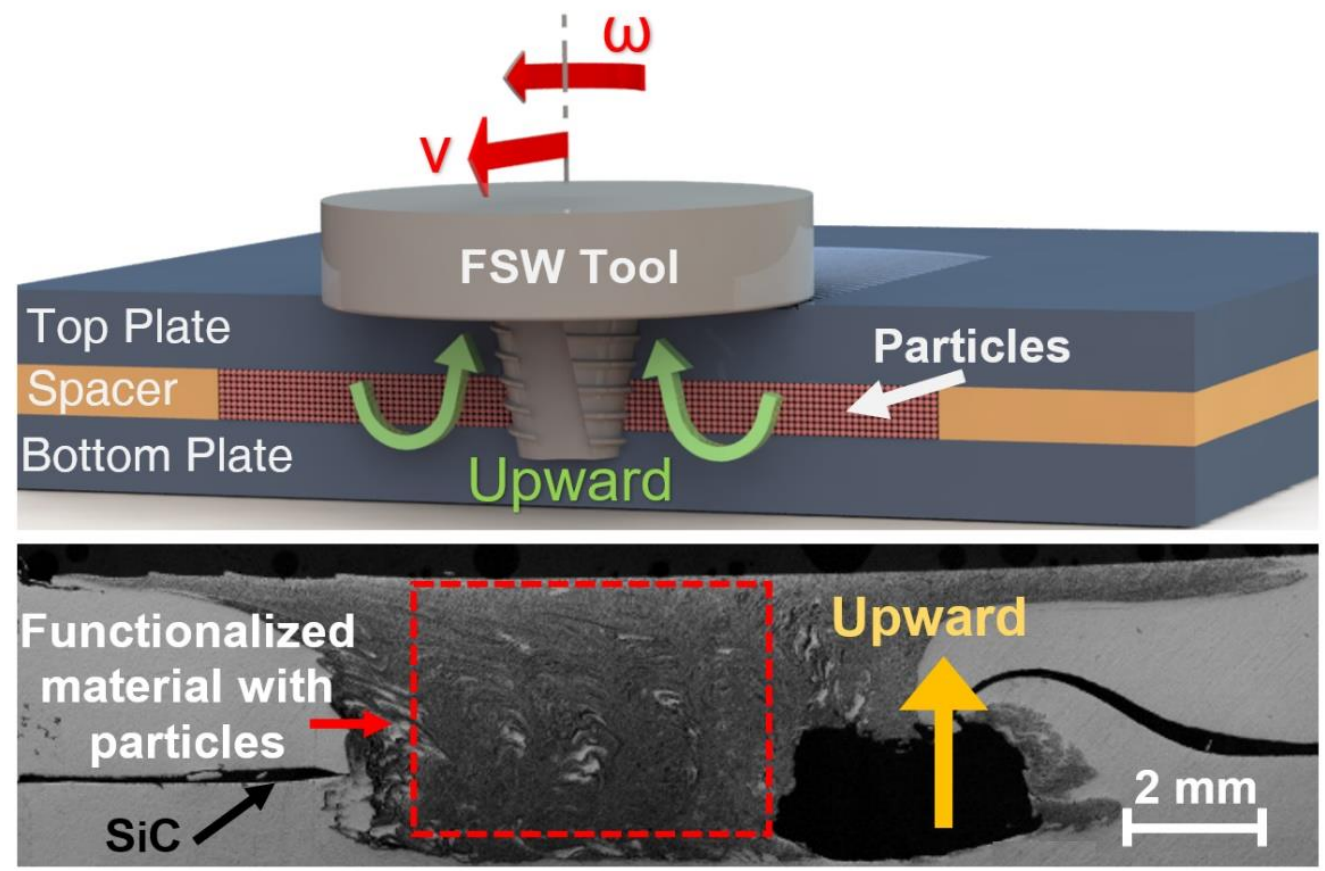




\begin{abstract}
An innovative friction stir processing variant, named Upward Friction Stir Processing (UFSP), for producing customized materials with multifunctional particles is presented. In the UFSP, an upward flow is used to disperse these functional particles in a metallic matrix, in opposition to the widely used downward flow. As a proof of concept, $\mathrm{SiC}$ particles were introduced and dispersed into an aluminium alloy AA7075-T651 matrix to study different process parameters and to validate this novel material processing technology. Six different small-sized ingots were produced and compared to the conventional FSP technology. The microstructural evolution is studied by means of optical microscopy, eddy current testing, microhardness mapping and advanced characterization techniques, such as, high energy synchrotron X-ray diffraction, scanning electron microscopy, energy-dispersive X-ray spectroscopy and electron backscatter diffraction. The number of passes was seen to greatly impact the particle distribution. Additionally, UFSP promotes a more uniform particle distribution over a larger processed area, when the lateral tool offset progress along the retreating side.
\end{abstract}

Keywords: Friction, Processing, Functional, Particles, Aluminium, SiC, NDT\&E, Characterization, Solid-State.

\title{
1. Introduction
}

Fusion-based processes, such as wire and arc additive manufacturing ${ }^{[1]}$ or laser processing ${ }^{[2]}$, have been used to functionalize materials, via the introduction of particles or inoculants elements into the melt pool. Such strategies allow to produce materials with different, improved, or customized features/properties, which include: grain refinement ${ }^{[3,4]}$ or increase in hardness and wear-resistance ${ }^{[4-6]}$.

However, the high temperatures that occur during fusion-based processes, prevents the use of several potential interesting particles (eg. solid antibiotics, antibacterial, antifungal particles or pharmacologic substance ${ }^{[7]}$, or anti-corrosion particles ${ }^{[8]}$, since the active ingredient of such particles is destroyed during the process, or because high-temperature chemical reactions lead to undesirable and prejudicial material properties. 
In these cases, solid-state material processing technologies can be an alternative route to produce such functionalized materials, since the temperature involved can remain below $250-300{ }^{\circ} \mathrm{C}$, depending on the material being processed and on the selected process parameters. Instead of blending particles in a melted material, solid-state processing, via Friction Stir Processing (FSP), can be used to introduce and distribute particles, in a metallic matrix, by viscoplastic stirring phenomena.

In fact, the production of functional materials, such as metal matrix composites (MMC) produced by FSP, have been often developed for targeting traditional engineering applications, namely, for high specific mechanical strength and wear resistance ${ }^{[9-11]}$. However, the potential of Friction Stir-based processes can go beyond the traditional mechanical oriented purposes if more effective stirring techniques are develop ${ }^{[12]}$. Therefore, FSP variant technologies able to produce these materials are required. FSP has been investigated for MMC manufacturing and various reinforcement methods are described in the literature. The earliest known technique comprises the direct pasting of a layer of powder ceramic particles mixed with methanol on the base material matrix and its subsequent processing ${ }^{[13]}$. Regardless of the development of different procedures and methods of particles deposition on metallic matrices, those involving machining/drilling of grooves/holes have been the most commonly used reinforcement techniques to produce MMC by FSP ${ }^{[14,15]}$. In the groove technique, one or more grooves are machined on the substrate surface and filled in with particles, which are then either compacted in the groove(s) (usually using a probeless tool ${ }^{[16]}$ ) or covered with a thin metal sheet to avoid particles sputtering during manufacturing ${ }^{[17,18]}$. Alternatively, it was demonstrated that the particles can be stacked between two plates ${ }^{[19,20]}$. The metallic matrix/functional particles arrangement is then processed by FSP. A similar procedure is adopted in the blind hole technique, a pre-established blind hole pattern is drilled on the metallic matrix surface and the holes are then filled in with particles and processing afterwards. It was claimed that a more uniform distribution of the functional particles in the metallic substrate is achieved by using this last technique ${ }^{[21,22]}$. In fact, a novel multi-hole pre-setting model was proposed, preventing agglomeration and loss of particles, thus promoting homogeneous distribution of NiTi particles ${ }^{[22]}$. Notwithstanding, Rathee et al. ${ }^{[14]}$ reported that combining the groove and the tool offset techniques promotes the production of more homogenous MMC when compared to those manufactured through the blind hole technique.

Guo et al. ${ }^{[23]}$ assessed the effect of the number of tool passes on the distribution of nano-sized aluminium oxide particles in an AA6061 substrate. The authors pre-placed the particles in the 
aluminium plate using the blind hole technique and found that multiple tool passes promote more homogeneous composites. The most promising results were obtained after the fourth tool pass. Yuvaraj et al. ${ }^{[24]}$ carried out a similar study by introducing micro and nano-sized boron carbide particles in an AA5083 matrix using the groove method for particles pre-placement. The number of tool passes were varied from one to three. Although particles' agglomeration was observed in the composites produced with a single pass, these authors found out that the following tool passes tend to either reduce or eliminate the agglomerates by redistributing the particles in the metallic substrate. Nascimento et al. ${ }^{[25]}$ reported that work-hardening aluminium alloys tend to require more passes than the heat-treated ones to achieve a homogenous processed region. Gandra et al. ${ }^{[26]}$ investigated the effect of the overlapping direction in multi-pass FSP and concluded that overlapping by the advancing side led to a more uniform particles distribution along the base material thickness, while overlapping by the retreating side tend to produce smoother surfaces.

From the literature, it could be concluded that, although, numerous FSP based techniques and strategies are in practice, none of them ensure a three-dimensional distribution of the functional particles as some envisages manufacturing of superficial functional materials ${ }^{[27]}$, and the ones assessing the volume lead to non-uniform distribution of particles with significant cluster acting as structural imperfection. In all these, the tool wear is a significant problem when hard abrasive particles are used to reinforce aluminium-based matrix.

In this work, a new FSP-based alternative for the production of functionalized materials incorporating any kind of solid particles is proposed. According to this novel variant, an upward viscoplastic material flow is promoted by pulling up the functionalized particles from the bottom of the tool probe to its top, allowing for a more uniform and three-dimensional distribution of the particles in the metal matrix. Moreover, the number of FSP passes required to enhance the homogeneity of the processed material, as well as, the overlapping direction in multi-pass processing are assessed.

\section{Process innovation: multi-stack Upward FSP (UFSP)}

Current FSP variants used for producing metallic composites are mostly based on a setup where the reinforcement particles can be in open or sealed grooves, drilled holes or simply deposited on the surface of the plate. The tool used is essentially the same as that used in conventional FSW, where the main goal is to promote a downward material viscoplastic flow. So far, all 
existing FSP variants focus on bringing the particles from an upper level to a lower level, i.e., from the top surface into the plate.

The proposed Upward Friction Stir Processing (UFSP) variant changes that point of view. Two sheets (where the bottom one can be a sacrificial plate) are assembled with any functional particles in between them. Then, the UFSP variant promotes an "aspiration" effect (upward flow). With such an approach, it is possible to introduce more particles with a more uniform distribution over the processed volume when compared to the conventional FSP approach, since the particles are continuously confined between the two plates, instead of being enclosed in discrete holes or grooves.

The upward flow effect can be achieved, for right-hand thread, by a clockwise rotation of the tool. To ensure the desired quantity and the uniform distribution of the functional particles in between the two sheets, a spacer is used. Additionally, the spacer also prevents sputtering of the particles. The schematic of the UFSP variant is depicted in Figure 1.

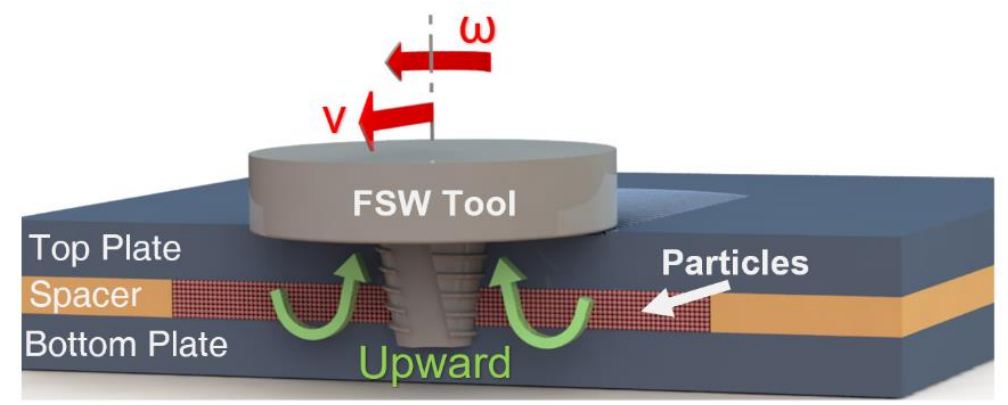

Figure 1 - Schematic representation, not to scale, of the Upward Friction Stir Processing (UFSP) for left-hand thread.

UFSP can reduce the sheet preparation and setup time before processing, since there is no need of machining grooves or drilling holes in the base material plates, the sealing step commonly used can be suppressed. Using a heat resistant and low rigidity spacer, enables to compact the particles during the thermomechanical processing. The fact that particles are constrained, prevents their release during the processing. This feature can also have an economic benefit, since expensive particles can be used, and its waste can be minimized. Moreover, UFSP is not limited to a linear trajectory, allowing free path planning. All the improvements described above might have a positive impact on productivity. 


\section{Materials and methods}

A multi-stack functionalized material was produced using aluminium plates AA7075-T651 with dimensions of 200 (rolling direction) $\times 100 \times 3 \mathrm{~mm}^{3}$ as base material. The nominal composition of the Al plates is depicted in Table 1. Silicon carbide (SiC) microparticles, with $99,5 \%$ of purity, were used for validation purposes, even though many other functional particles can be used, depending on the desired functionality for the base material. The $\mathrm{SiC}$ particles were characterized by scanning electron microscopy (SEM), as depicted in Figure 2. Its shape is not uniform, the particle size ranges between 4 to $20 \mu \mathrm{m}$, with an average diameter of $6 \mu \mathrm{m}$. The particles were placed between two plates and surrounded by a Kapton ${ }^{\circledR}$ tape to prevent its waste and to level the upper aluminium plate while enabling compacting of the particles during the thermomechanical processing. Preliminary trials were carried out to evaluate the maximum particles' layer thickness in which this experimental setup remains feasible. It was found that, when the thickness of the $\mathrm{SiC}$ layer of particles was below $1 \mathrm{~mm}$, the process is feasible, while above this threshold, clusters of particles would form inside the aluminium matrix, affecting the mechanical resistance. In fact, for particles' layer thickness above $1 \mathrm{~mm}$ the volume fraction of particles/aluminium becomes inviable, preventing an effective embedment of SiC particles in the aluminium matrix. Moreover, powder bed higher than $1 \mathrm{~mm}$ leads to the collapse of the upper plate, since lateral constrain provided by the Kapton ${ }^{\circledR}$ tape was not able to hold the particles. The experimental setup was mounted, as shown in Figure 3, on a backing plate and fixed by four M8 bolts.

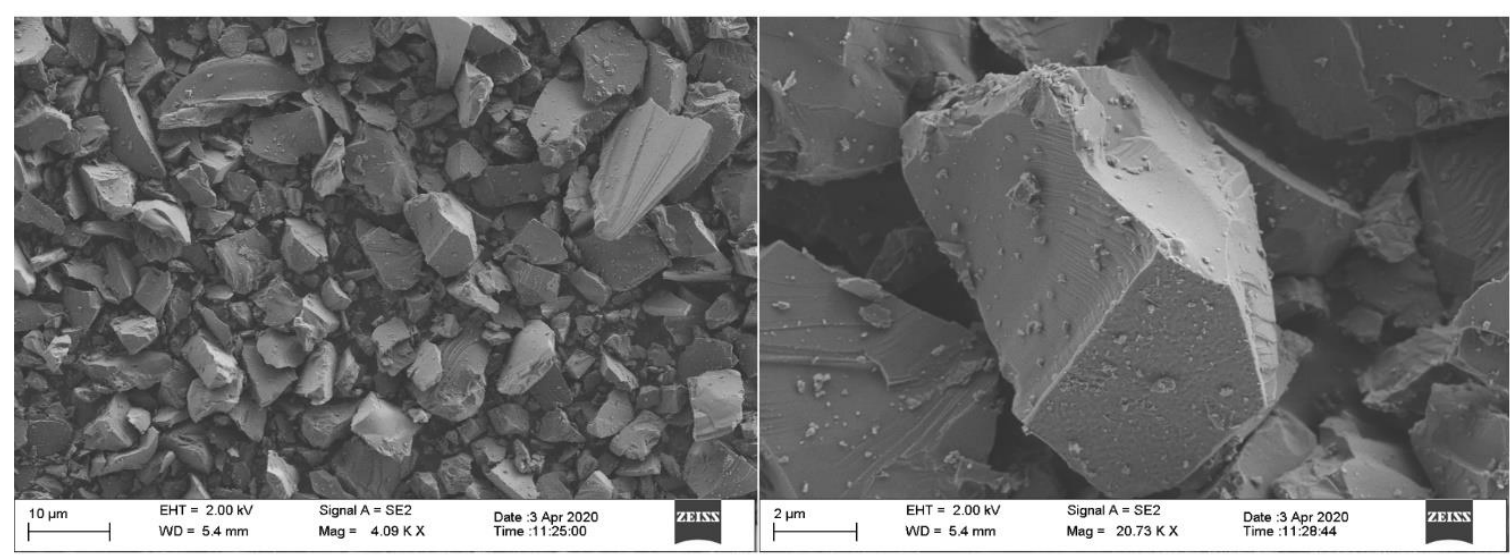

Figure 2 - SiC particles morphology and dimension observed by SEM. 


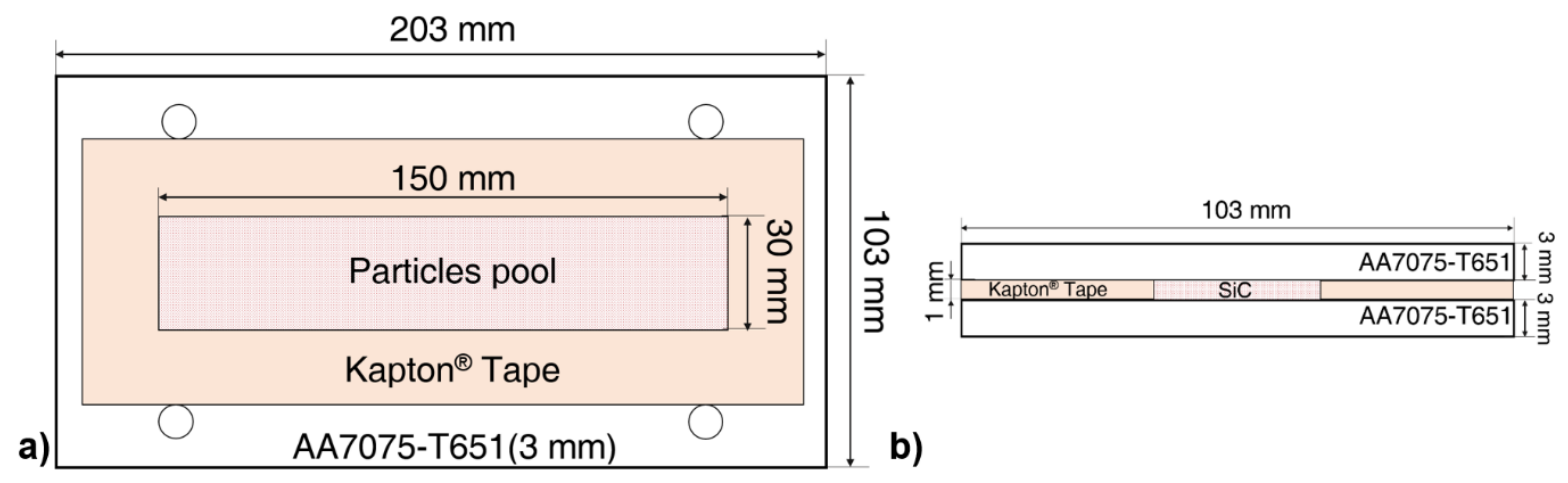

Figure 3 - Experimental setup of the composite for production by friction stir processing: a) Top View; b) Transversal view.

Table 1 - Chemical composition of AA7075-T651 Aluminium Alloy.

\begin{tabular}{cccccccccc}
\hline Elements & $\mathrm{Al}$ & $\mathrm{Cr}$ & $\mathrm{Cu}$ & $\mathrm{Fe}$ & $\mathrm{Mg}$ & $\mathrm{Mn}$ & $\mathrm{Si}$ & $\mathrm{Ti}$ & $\mathrm{Zn}$ \\
\hline (wt\%) & remnant & $0.18-0.28$ & $1.2-2.0$ & 0.5 & $2.1-2.9$ & 0.3 & 0.4 & 0.2 & $5.1-6.1$ \\
\hline
\end{tabular}

A FSW/P tool made of H13 steel with a concave shoulder of $16 \mathrm{~mm}$ diameter and a triflute left-hand threaded conical probe of $6 \mathrm{~mm}$ of diameter and $6 \mathrm{~mm}$ of length was used. The tool was tilted by $1^{\circ}$ and the tool rotation and processing speed were $900 \mathrm{rev} / \mathrm{min}$ and $180 \mathrm{~mm} / \mathrm{min}$, respectively, for all composites produced, leading to a $\Omega / \mathrm{V}$ ratio of $5 \mathrm{rev} / \mathrm{mm}$. To evaluate the effect of the upward variant on the particles distribution, three distinct case studies were performed, as described in Table 2: i) effect of one pass for counter-clockwise (CCW) and clockwise (CW) tool rotations; ii) effect of four fully overlapping passes at CCW and CW tool rotations; iii) six passes with tool offset of $1 \mathrm{~mm}$ between passes towards advancing side and retreating side. 
Table 2 - Experimental plan to evaluate the effect of the processing parameters on UFSP.

\begin{tabular}{|c|c|c|c|c|}
\hline $\begin{array}{l}\text { Sample } \\
\quad \# .\end{array}$ & $\begin{array}{l}\text { No. processing } \\
\text { passes }\end{array}$ & Particles & $\begin{array}{l}\text { Tool rotation } \\
\text { direction }\end{array}$ & $\begin{array}{l}\text { Tool transverse } \\
\text { direction }\end{array}$ \\
\hline$\# 1$ & 1 & $\mathrm{SiC}$ & $\mathrm{CCW}$ & - \\
\hline$\# 2$ & 1 & $\mathrm{SiC}$ & $\mathrm{CW}$ & - \\
\hline$\# 3$ & 4 & $\mathrm{SiC}$ & $\mathrm{CCW}$ & No step offset \\
\hline$\# 4$ & 4 & $\mathrm{SiC}$ & $\mathrm{CW}$ & No step offset \\
\hline$\# 5$ & 6 & $\mathrm{SiC}$ & $\mathrm{CCW}$ & $\begin{array}{l}1 \mathrm{~mm} \text { step offset to } \\
\text { advancing side }\end{array}$ \\
\hline \#6 & 6 & $\mathrm{SiC}$ & $\mathrm{CCW}$ & $\begin{array}{l}1 \text { mm step offset to } \\
\text { retreating side }\end{array}$ \\
\hline$\# 7$ & 6 & No Particles & $\mathrm{CCW}$ & $\begin{array}{c}1 \mathrm{~mm} \text { step offset to } \\
\text { advancing side }\end{array}$ \\
\hline
\end{tabular}

Temperature measurements were carried out using 23 thermocouples placed in the backing plate and 4 in between the backing plate and the AA7075-T651 bottom plate, as well as a Fluke Ti400 infrared camera for surface measurements.

After processing, samples were prepared for the different characterization techniques. The samples for macro and micrography were grounded and polished following standard metallographic procedures and then etched in Keller reagent during three to six seconds. For eddy current characterization the top surface of the sample was machined down, grounded and polished to obtain a homogenous surface condition. On the same surface, microhardness profiles were also obtained.

Macro and micrography analysis were performed using an Olympus CX40RF200 optical microscope to reveal the microstructure and particle distribution. Sequential images were taken and merged to create a high-resolution image of the cross-section.

A Mitutoyo HM-112 hardness testing machine was used to measure the microhardnessVickers profile along the length of the samples. The spacing between consecutive indentions was of $1 \mathrm{~mm}$ for the base material and $0.5 \mathrm{~mm}$ for processed and thermal/mechanical affected regions. The load used was $0.3 \mathrm{kgf}$.

Eddy current technique was used to characterize the electrical conductivity of the sample according to the procedure used by Sorger et al. ${ }^{[28]}$ and Santos et al. ${ }^{[29]}$. Such technique allows to evaluate fine microstructure changes in a reliable and expedite way. An eddy current pencil probe operating at 100 and $500 \mathrm{kHz}$ (corresponding to a penetration depth of 0.37 and 0.16 
$\mathrm{mm}$, respectively) was used with a NORTEC 500C impedance analyser. The electrical conductivity profile was performed in the transversal section of the samples.

Synchrotron X-ray diffraction was performed at the High Energy Materials Science P07 beamline at PETRAIII/DESY. A wavelength of $0.14325 \AA$ was used, which allowed to work in transmission mode. The diffraction cones were captured using a 2D Perkin Elmer fast detector. The X-ray beam was focused on the base material and stirred region to evaluate the microstructural changes induced by the UFSP variant. Treatment of the raw data was performed using Fit2D developed by Hammersley et al. ${ }^{[30]}$ and using the procedure described by Oliveira et al. ${ }^{[31]}$.

To prepare the samples for EBSD, the samples were then ground using 800, 1200 and 2400 grit paper before being polished with 3,1 and $0.25 \mu \mathrm{m}$ diamond compound on a Struers LaboPol-5 machine, with a final polishing being done using a Buehler Vibromet 2 vibration polisher on Microcloth fabric with $0.02 \mu \mathrm{m}$ colloidal silica suspension for 3 hours. The scanning electron microscopy (SEM), energy-dispersive X-ray spectroscopy (EDS) and electron backscatter diffraction (EBSD) were done using a Zeiss Ultra 55 SEM equipped with Bruker XFlash EDS detector, and Nordlys EBSD detector.

\section{Results and discussion}

\subsection{Temperature measurements}

Figure 4 shows the maximum temperature values recorded by the thermocouples during single and multi-pass processing and the temperature field at time instant $65 \mathrm{~s}$ and $450 \mathrm{~s}$, respectively. Thermocouple measurements revealed peak temperatures about $350^{\circ} \mathrm{C}$ during processing. The temperature raised up during the tool's plunge stage and was almost constant during processing. It is during the tool's plunge stage that the initial heat generation and plastic deformation stage occurs. From Figure 4, one can observe that: for multi-pass processing, the peak temperatures at each pass remain almost constant, regardless processing has started at around $100{ }^{\circ} \mathrm{C}$ or $200{ }^{\circ} \mathrm{C}$ and, the maximum temperature experienced by the material is not affected by the number of passes when using the same processing parameters. 

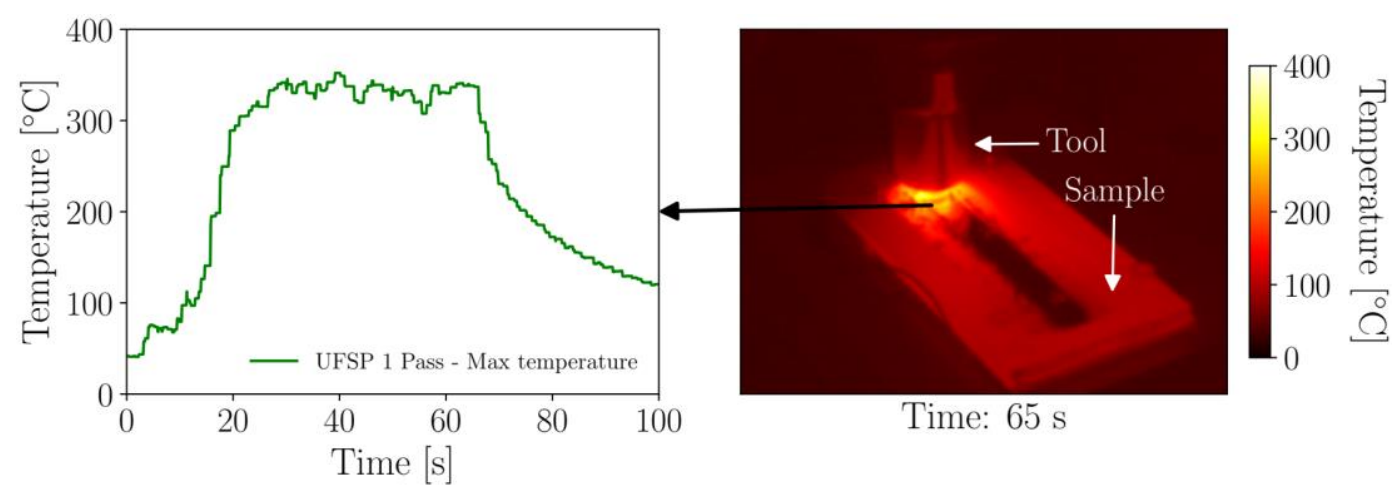

Time: $65 \mathrm{~s}$

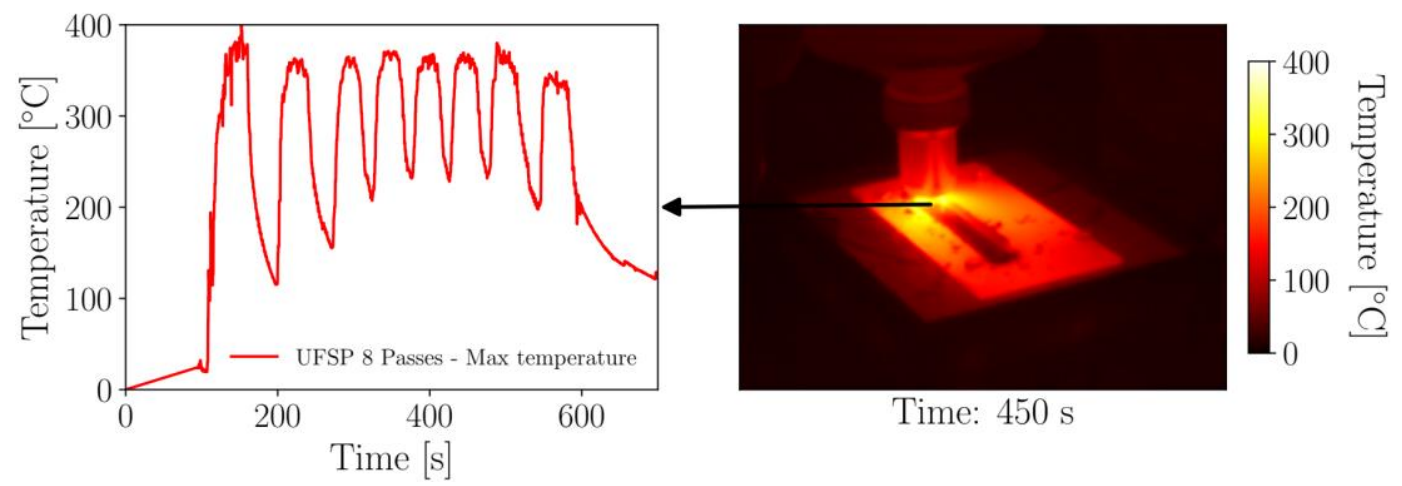

Figure 4 - Time-evolution of the maximum temperature during UFSP with 1 and 8 passes.

\subsection{Macrography Analysis}

Figure 5 depicts the macrographs of two processed materials produced with the novel UFSP variant (refer to Figure 5a, corresponding to sample \#1) and with conventional FSP (refer to Figure $5 \mathrm{~b}$, corresponding to sample \#2). There is an evident particle distribution in the upper plate of sample \#1 proving that the upward methodology was able to promote an ascendant material flow that brings the particles almost along the full thickness of the upper sheet. Furthermore, the particles were preferentially distributed in the advancing side. In contrast, when the FSP was done in CW (sample \#2) the particles have not been distributed in the upper plate, though this upper plate has been processed. This suggests the existence of a concentration region where the particles were deposited. Such effect is attributed to the downward material flow typical of conventional FSP, that transported the particles from the middle of the probe to its bottom since the probe tread promotes the downstream of the material. 

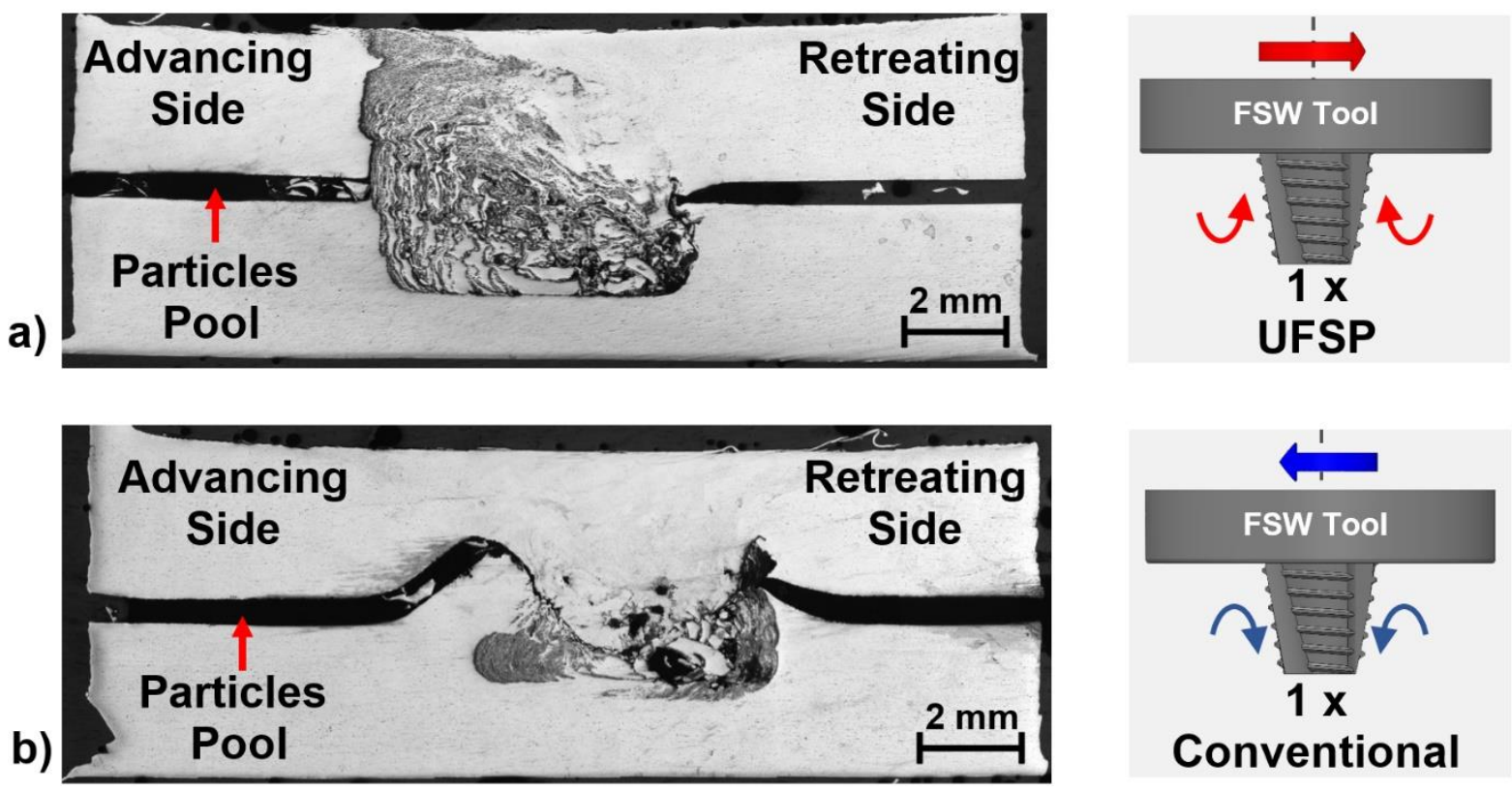

Figure 5 - Methodology performance in particle distribution: a) after one pass of UFSP; b) after one pass of conventional FSP.

From the macrography of sample \#1, shown in Figure 6, a good homogeneity was already achieved near the shoulder surface. However, a detailed analysis of the stirred zone depicts some heterogeneity regions and voids at the bottom of the tool probe.

a)

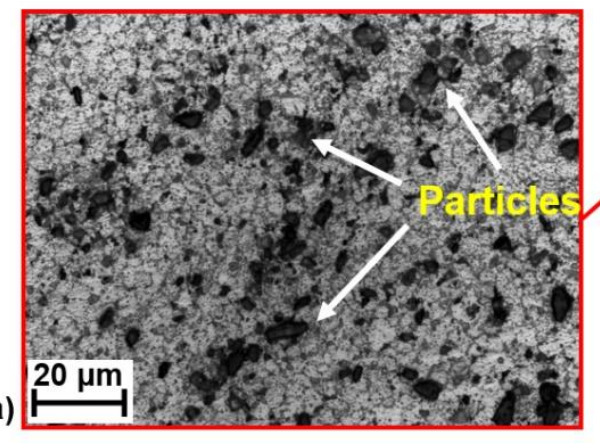

c)

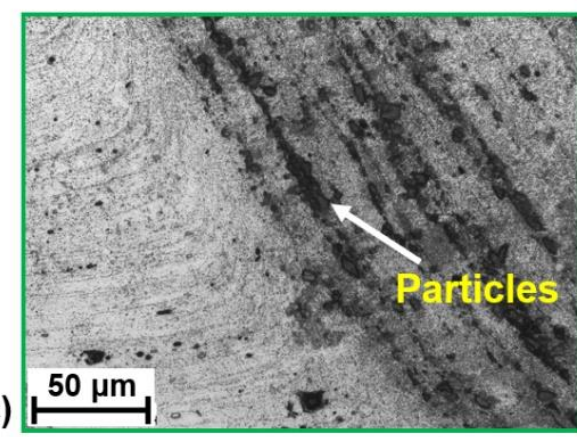

b)

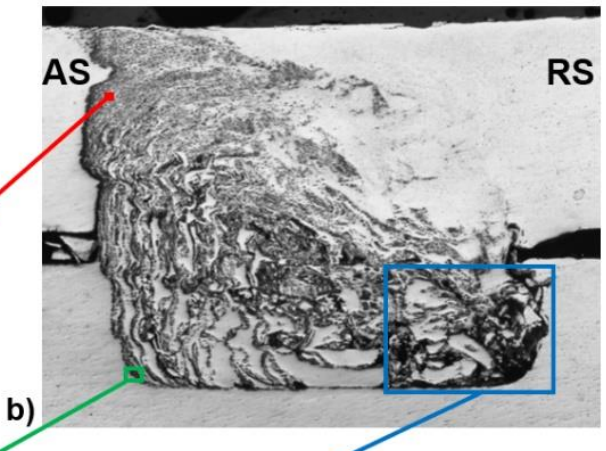

d)

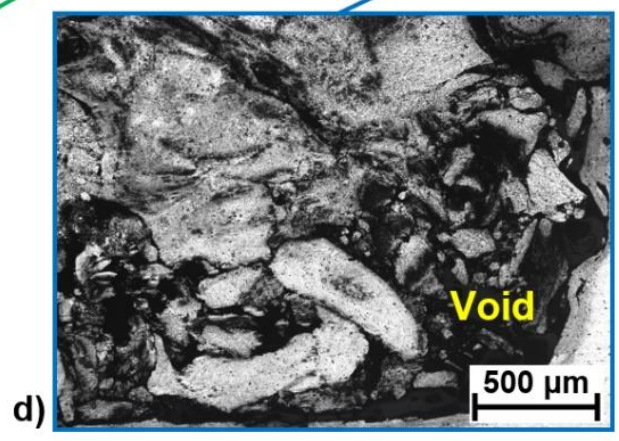

Figure 6 - Micrography of UFSP with one pass: a) Concentration of SiC particles near top surface; b) Nugget Zone; c) Cluster of SiC particles; d) Void at the bottom of the nugget zone due to lack of pressure. 
The final particle distribution reflects the material flow of the AA7075-T651 and the different levels of forging pressure within the stirred zone. Near the shoulder, the viscoplastic material flow is influenced by the combined actions of planar flow induced by the rotating shoulder and vertical flow induced by the probe action. At the tip of the probe, there is only the vertical flow induced by the probe action as claimed by Reynolds ${ }^{[32]}$. Considering these actions it is possible to understand the significantly different behaviour of the $\mathrm{CCW}$ and $\mathrm{CW}$ action on the particle distribution exhibited in Figure 5 and emphasized in Figure 6. In the conventional FSP the particles are exclusively influenced by the stirring effect induced by the probe, that takes the particles from his mid-section pushing them down, resulting in significant volumes of highly pressurized clusters of particles mostly localized at the root of the stirred zone. The typical upward flow of the interface of the plates, sometimes forming hooks-like shapes, and well known from overlapping FSW, is visible in the Figure 5b. Any voids in the conventional FSP, will be generated due to the high density of particles preventing the aluminium alloy from flowing and fill all zones left empty in the trailing side of the travelling probe. In opposition, the novel UFSP alternative with one pass only already delivers one impressive quasi-uniform distribution of the particles within the solid phase of AA7075. In the micrograph of Figure 6a, near the shoulder, it is possible to confirm that the uniform distribution is based on small size clusters of particles, no bigger than $20 \mu \mathrm{m}$, with consolidated all-round aluminium as expected in a sound MMC microstructure. Dialami et al. ${ }^{[33]}$ indicated that the quality of the fine dispersion of particles decreases from the face towards the root zones of the stirred zone as the combined shoulder + probe + high forging pressure effect on the material flow disappears. Thus, the exception to this optimal fine dispersion condition is the root of the processed zone, mostly at the retreating side (Figure 4d). This is due to the local reduction of forging pressure to consolidate the aluminium flow in that zone, as the probe as an essentially upward action. Also, near the shoulder at the retreating side, there is an AA7075 rich zone that was broughtin by the trailing edge of the rotating shoulder. But in general, the in-volume quality of the fine dispersion of particles is one of the best in state of the art, using FSP's technique.

Figure 7 depicts the two composites produced with overlapping 4 passes for sample \#3 (Figure 7a) and for sample \#4 (Figure 7b) - with the UFSP and conventional FSP variants, respectively. Despite the existence of a flow arm, also showed by Pashazadeh et al. ${ }^{[34]}$, from the retreating side in sample \#3, the particle homogeneity in the advancing side was achieved. Although a slight improvement of the distribution of particles over the advancing side and near the shoulder, the improvements from one pass is not significant, as for one pass the results were 
already quite good. Near the root of the stirred zone the AA7075 consolidation is still poor due to lack of forging pressure.

The increased number of passes promoted the dispersion of the functional particles in the matrix when comparing sample \#4 with sample \#2 (conventional FSP variant with four and one pass, respectively). This is in good agreement with founds in other works on FSP ${ }^{[23,27]}$. Despite of the fact that the $\mathrm{SiC}$ particles are well distributed, the induced material flow was not enough for the particles to reach the top surface. This is because the particles are not dragged towards the nugget. Thus, despite of the fact that material deformation occurs, the $\mathrm{SiC}$ particles are not fully incorporated into the processed area. It was observed a good homogeneity in the stirred zone, from the bottom of the tool probe to approximately $3 / 4$ of the probe length, with a slight increase in the advancing side.

The increase of the number of passes was found to be critical for the conventional FSP, but it seems to be not so crucial for UFSP. This outcome is of major importance in terms of productivity in manufacturing of Functional Graded Materials (FGM). Although, conventional FSP improves the uniformity of the particles distribution in the matrix, its limited upward action was not able to bring any significant amount of particles to the upper region of the sample, and the hook-like alignment of particles from the advancing side into the middle of the stirred zone, will act as a structural defect.
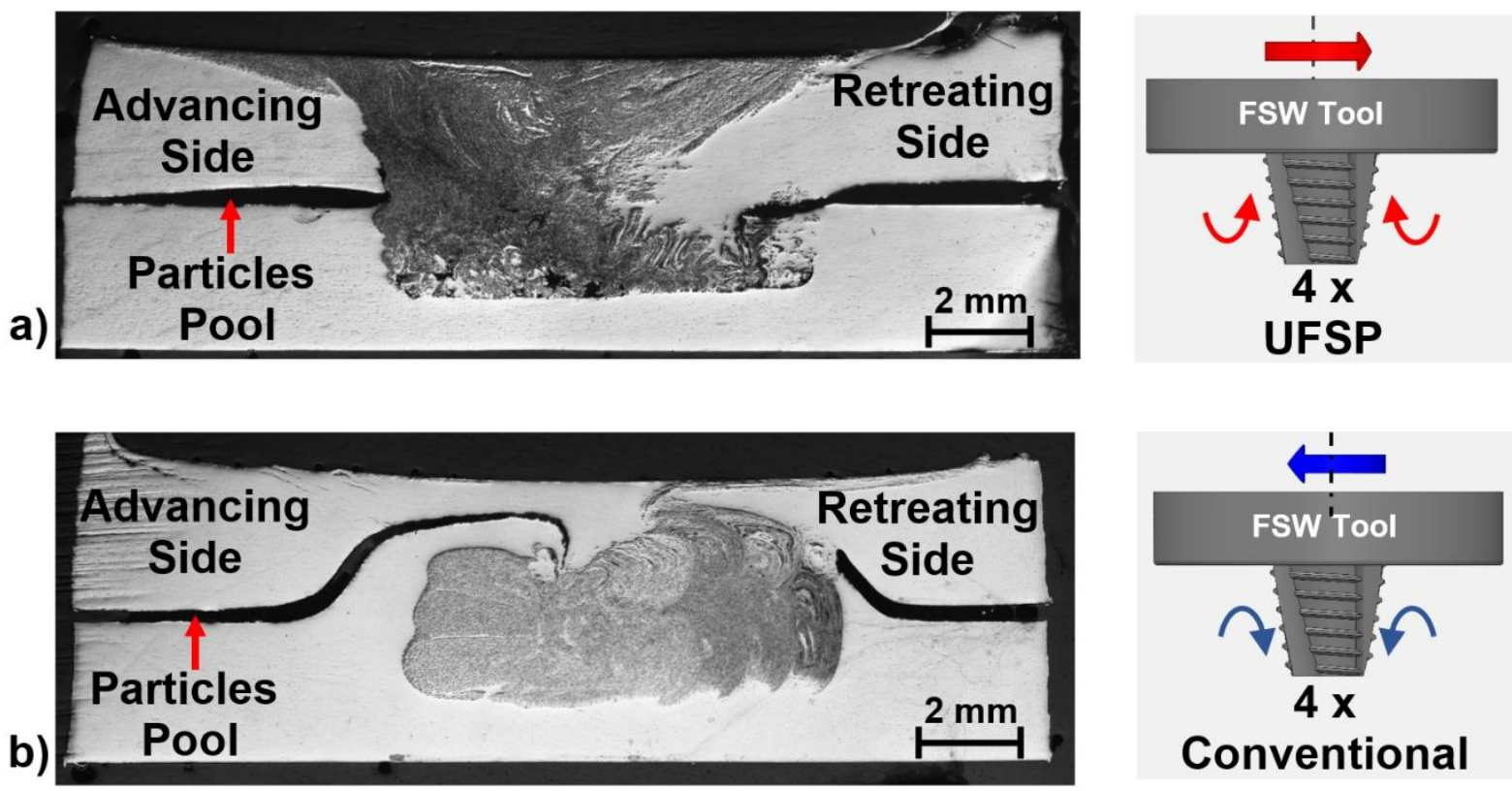

Figure 7 - Variant performance in particle distribution: a) after four passes of UFSP (sample \#3); b) after four passes of conventional FSP (sample \#4). 
The performance of the upward FSP variant was also evaluated in terms of the particles distribution, when the tool was moved in the direction of the advancing side or in the direction of the retreating side after six passes evenly spaced by $1 \mathrm{~mm}$. Considering the direction of the advancing side, corresponding to sample \#5, it was observed a heterogeneous distribution of the particles, due to the appearance of successive flow arms from the retreating side, as presented in Figure 8. This also means that the $\mathrm{CCW}$ tool rotation for a left-hand thread promotes a material flow from the retreating side to the advancing side.

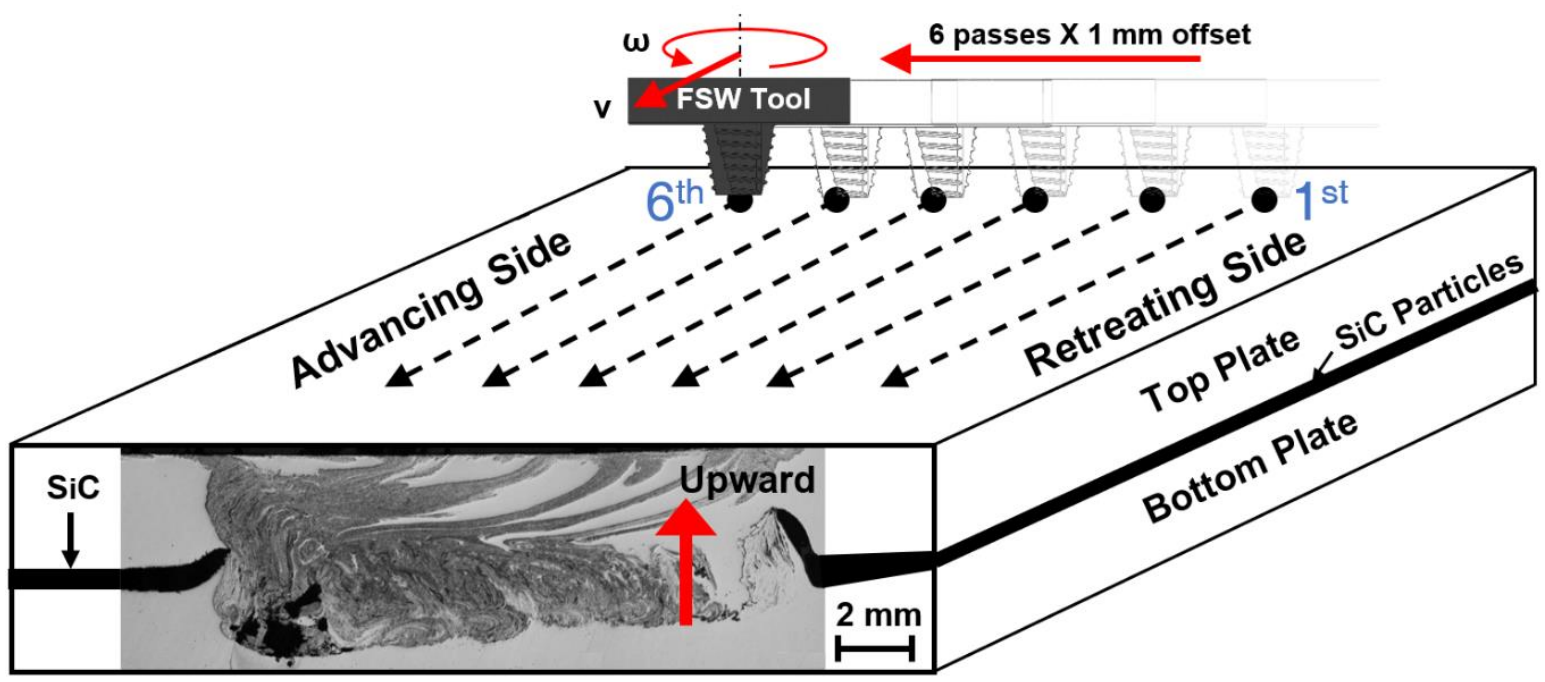

Figure 8 - Transversal section of the composite produced by UFSP variant after six passes spaced by $1 \mathrm{~mm}$ with tool offset in direction of advancing side (sample \#5).

In opposition, when the tool offset was in direction of the retreating side, the particle distribution was significantly improved, as depicted in Figure 9, where an excellent homogeneity inside the stirred zone was achieved when compared to sample \#5.

This improvement is in good agreement with the results of sample \#1 where the $\mathrm{SiC}$ particles are predominantly deposited in the advancing side, highlighting that the particles travel to that side. The addition of more processing steps towards the retreating side allows the admission of more particles into the stirred zone that were ultimately deposited in the advancing side. Regarding the appearance of a void, it was demonstrated that when an upward material flow is promoted, that eventually might cause a tunnel defect ${ }^{[35]}$. This void is an inherent consequence of the UFSP technology due to the "aspiration" effect induced which causes a sub-pressure condition at the root of the stirred zone. However, this is not a critical issue because the purpose of this process is not to manufacture a component with the two plates, but to produce high value small-sized ingots of an enhanced material with functional particles incorporated. This material 
will then be used as a base material for subsequent manufacturing processes (eg. machining, forming, welding) to produce small, customized products (eg. implants, sensors, actuators, high abrasive, and corrosion resistant components).

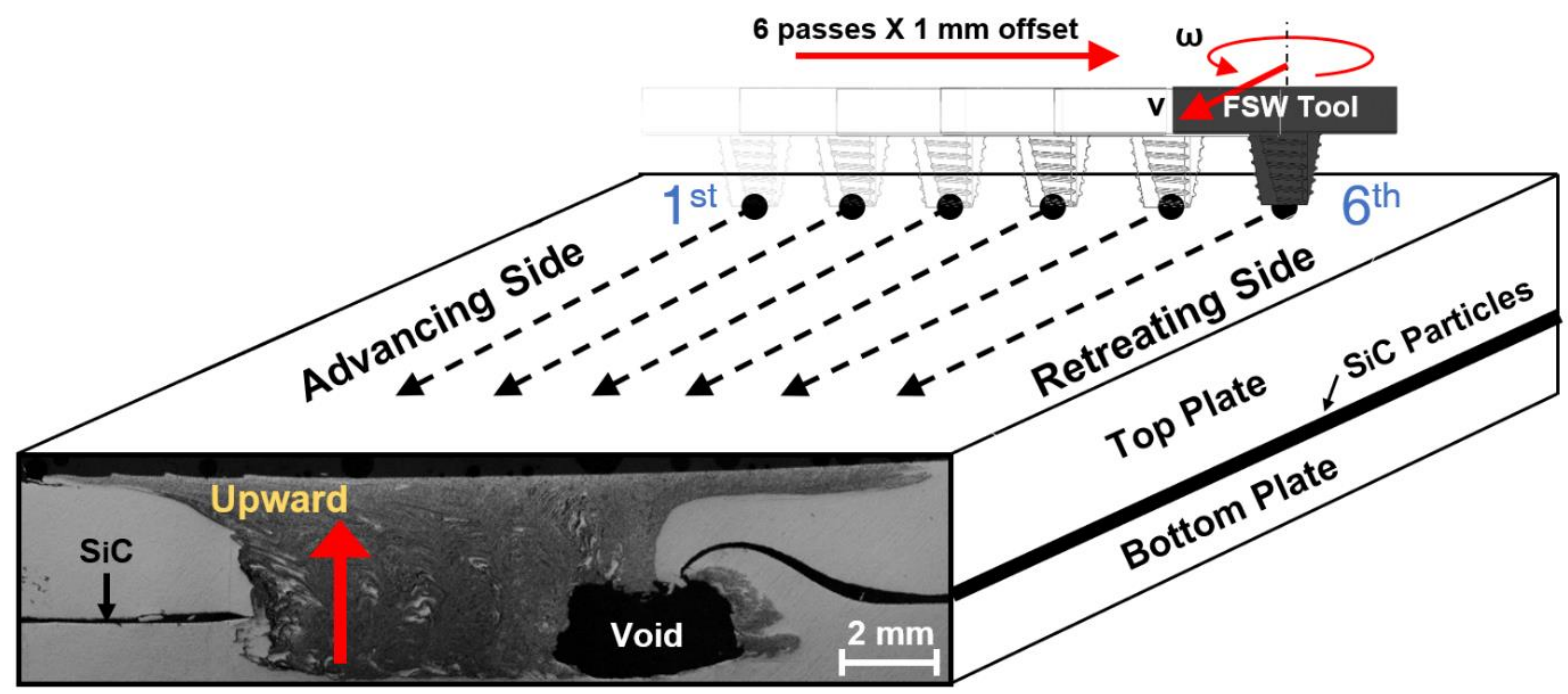

Figure 9 - Transversal section of the composite produced by UFSP variant after six passes spaced by $1 \mathrm{~mm}$ with tool offset in direction of retreating side (sample \#6).

\subsection{Microhardness and eddy current testing}

Microhardness measurements and eddy current testing were performed in the transversal section of the samples, $1 \mathrm{~mm}$ below the top surface to characterize the processed and nonprocessed zones, and to evaluate the particles distribution. Hardness can be also an indicator of the effect of the processing conditions in terms of mechanical strength since it is directly proportional to it. Eddy current testing is an expedite technique for assessing microstructural changes in thermomechanically processed materials, that is complementary to hardness measurements ${ }^{[36,37]}$. In fact, other works have shown that electrical conductivity is inversely proportional to hardness and consequently to the mechanical strength ${ }^{[28,29]}$. As such, refined zones have lower electrical conductivity, since more grain boundaries reduces the electronic mobility, while the thermal affected zones have higher conductivity due to the grain growth.

Figure 10 and Figure 11 depict the hardness and electrical conductivity profiles for one pass with UFSP and the conventional FSP variant, respectively. It is observed a slight ( $\approx 12 \mathrm{HV})$ decrease of hardness in the stirred zone when compared to the base material. The strengthening effect induced by the T651 heat treatment is lowered by a low temperature annealing experienced during processing. However, in the sample with the UFSP variant (sample \#1), the 
presence of $\mathrm{SiC}$ particles have increased the hardness in that region and, consequently the material hardness is higher there than in the base material. Eddy current testing are in good agreement with the obtained hardness profiles.

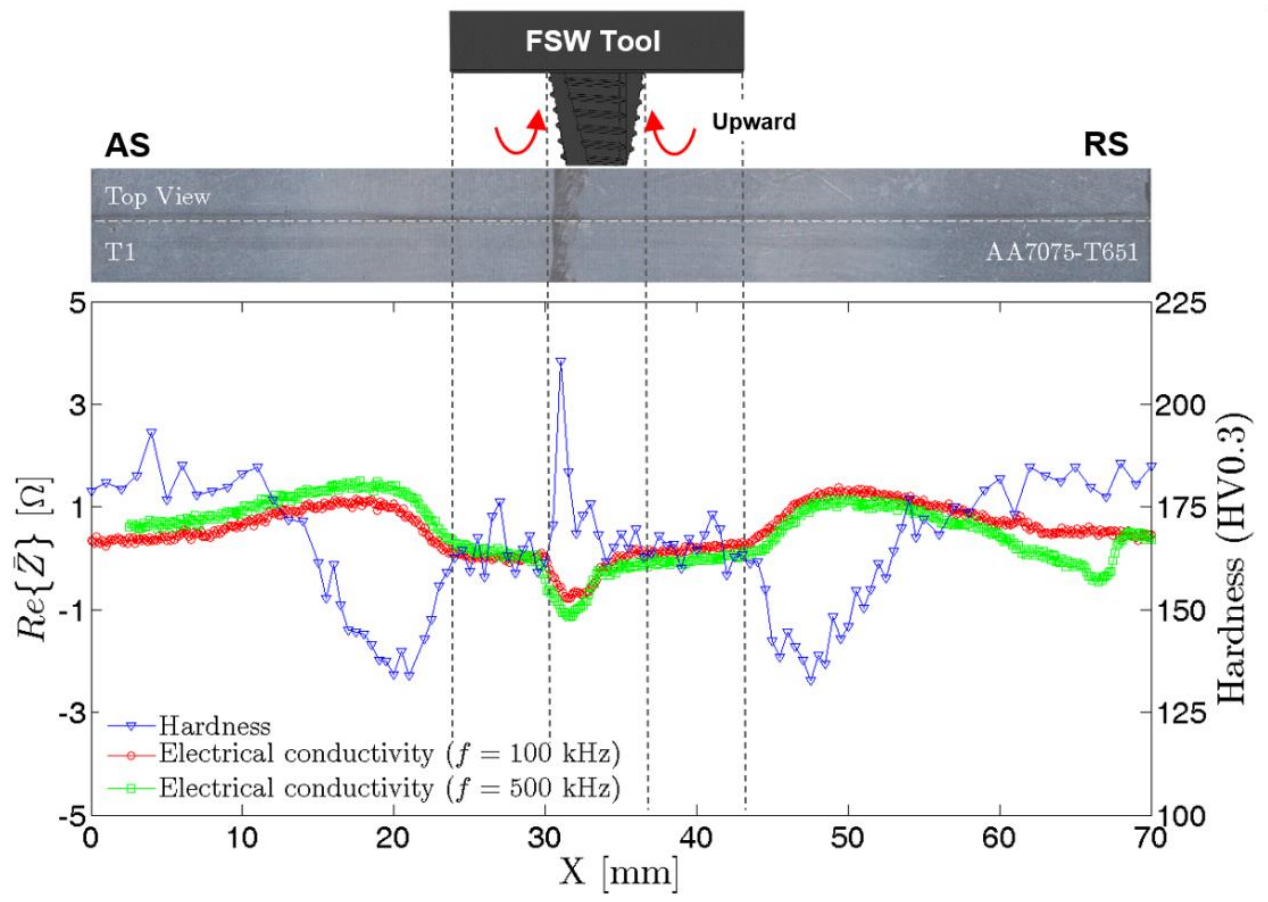

Figure 10 - Hardness and electrical conductivity profiles of UFSP variant with one pass (sample \#1).

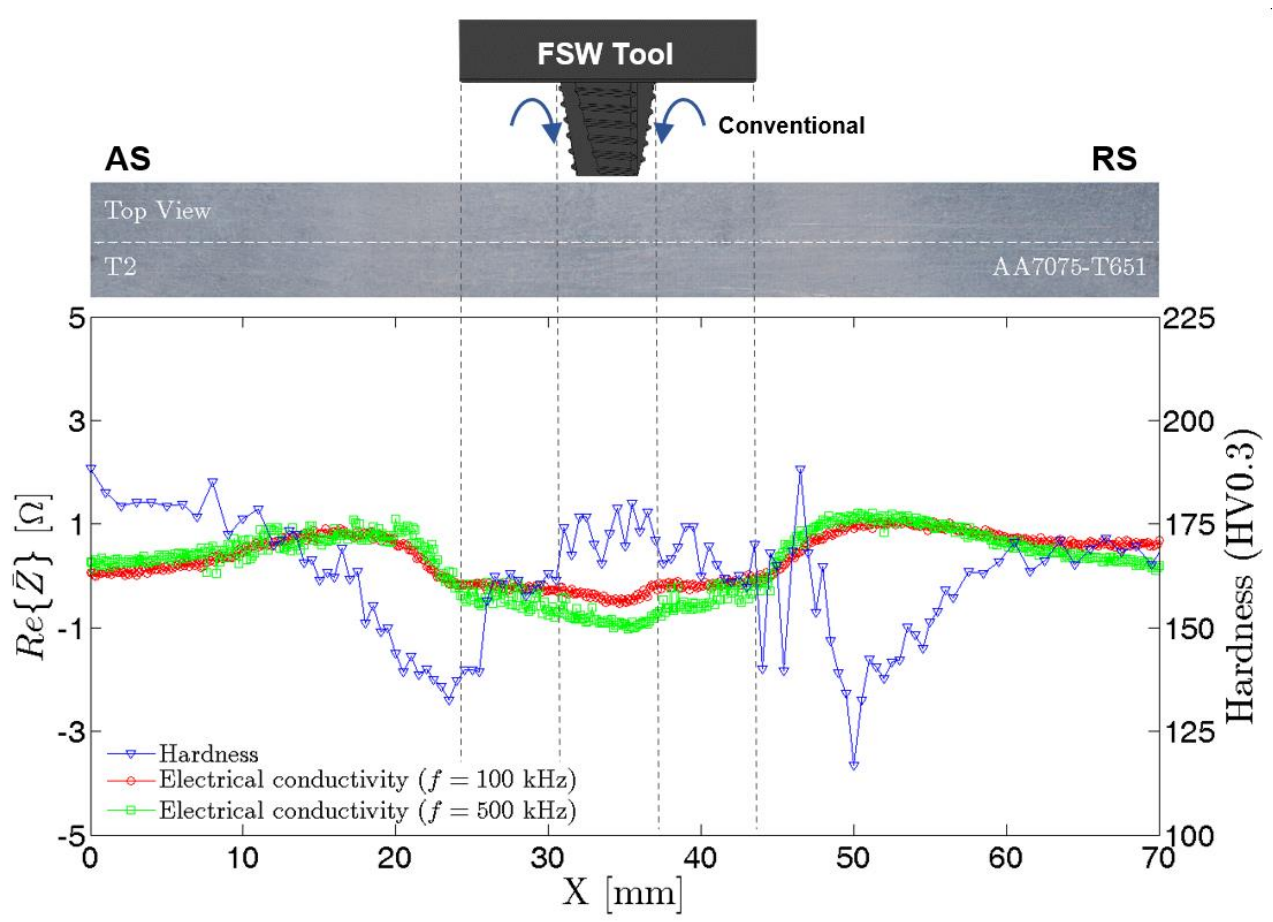

Figure 11 - Hardness and electrical conductivity profile of conventional FSP with one pass (sample \#2). 
For samples \#5 and \#6 the processing strategy was to offset the tool in each pass by $1 \mathrm{~mm}$ in direction of the advancing and retreating sides, respectively. This aimed to evaluate the $\mathrm{SiC}$ particles dispersion in the Al plate. From the macrography analysis it is possible to conclude that imposing an offset towards the advancing side promotes heterogeneity, while towards the retreating side promotes homogeneity. The hardness and electrical conductivity profiles plotted in Figure 12 and Figure 13 further highlight that evidence. For sample 5\#, a maximum hardness of $223 \mathrm{HV} 0.3$ inside the stirred zone was measured, whereas for sample $6 \#$ there is a uniform plateau hardness level in the stirred zone at $\approx 175$ HV0.3.

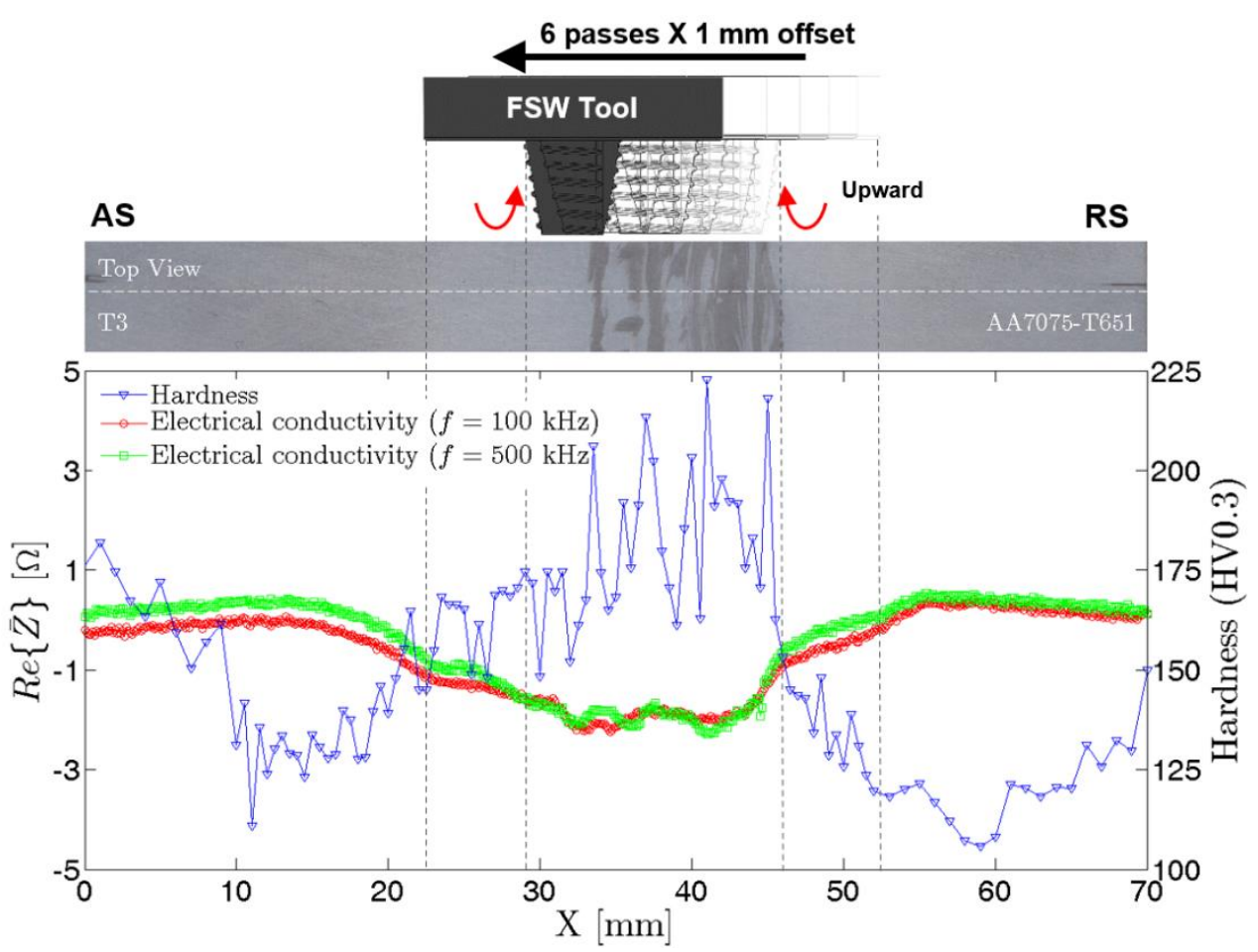

Figure 12 - Hardness and electrical conductivity profile of UFSP with 6 passes spaced by $1 \mathrm{~mm}$ in direction of advancing side (Sample \#5). 


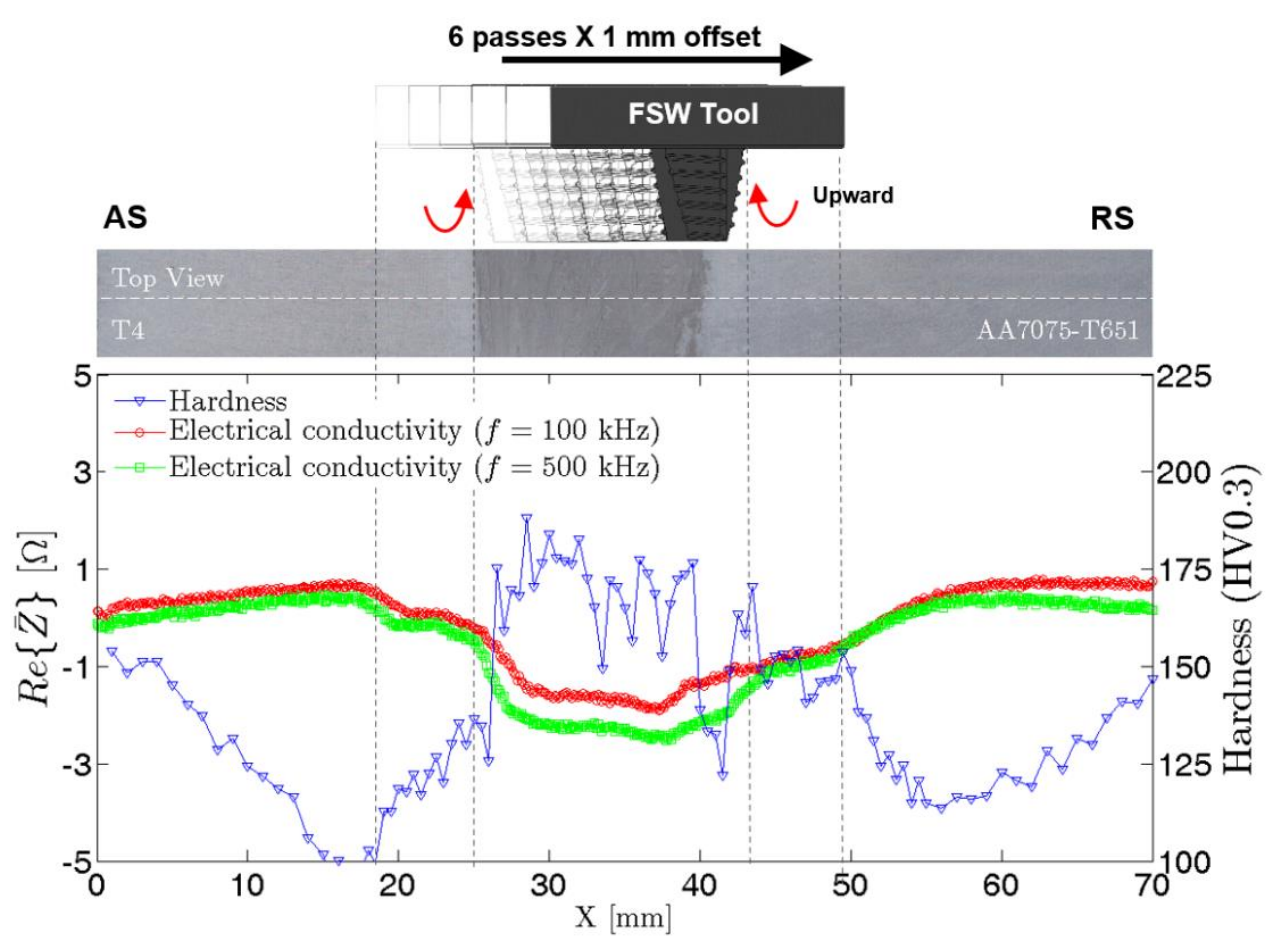

Figure 13 - Hardness and electrical conductivity profile of UFSP with 6 passes spaced by $1 \mathrm{~mm}$ in direction of retreating side (sample \#6).

The macrostructure, microhardness and electrical conductivity profiles of the sample produced without any particles, corresponding to sample \#7, is depicted in Figure 14. Both hardness and electrical conductivity profiles have a symmetrical-like shape, in good agreement with what was expected for this configuration without $\mathrm{SiC}$ particles. In terms of mechanical strength, the hardness of the stirred zone is at the same level as the base material level, without any significant improvement as previously observed for sample \#5 and sample \#6.

The hardness and electrical conductivity profiles previously presented show that the UFSP variant can modify the material properties, including mechanical resistance, especially when processing with tool offset moving towards the retreating side. 


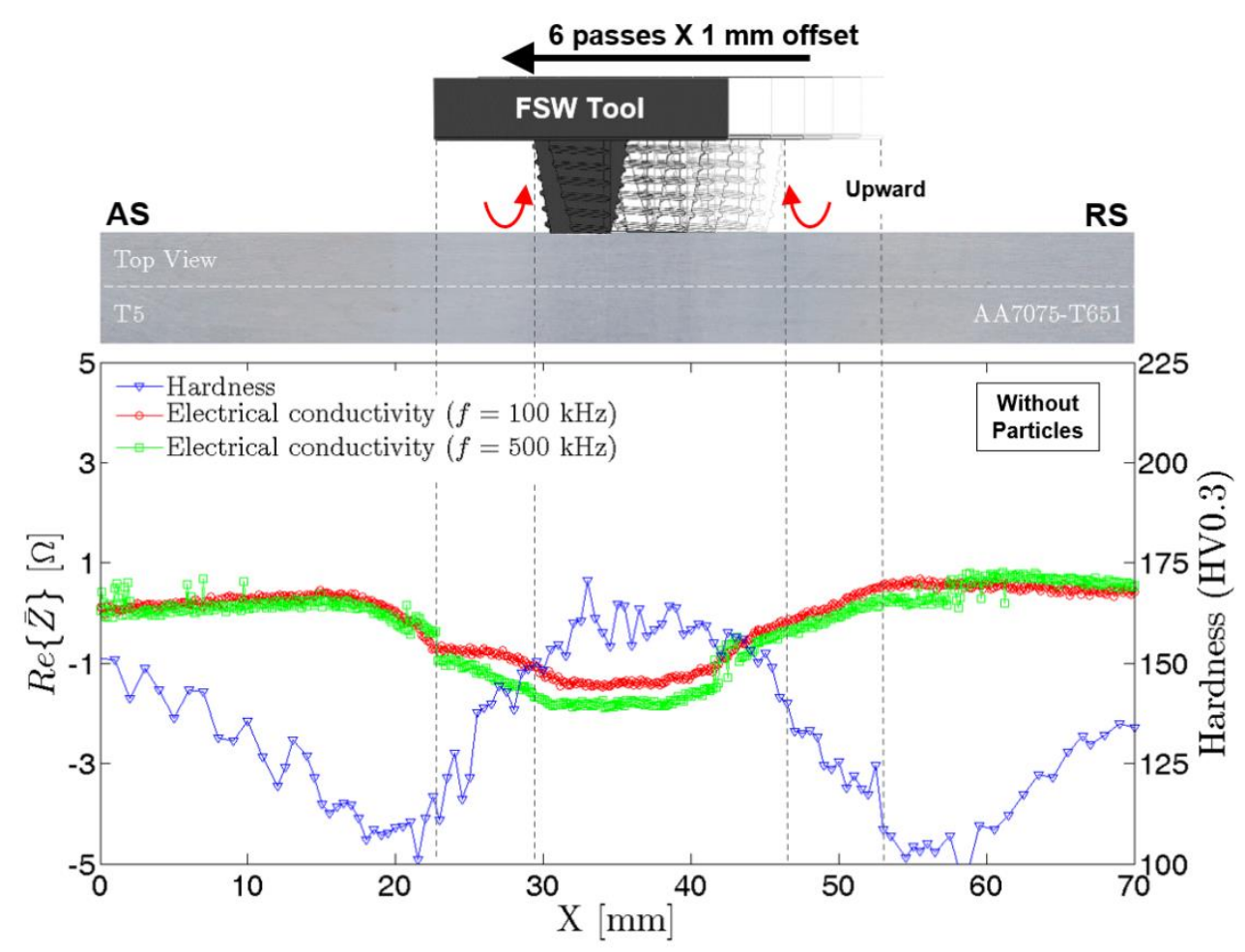

Figure 14 - Hardness and electrical conductivity profile of UFSP with 6 passes spaced by $1 \mathrm{~mm}$ in direction of advancing side and without particles (sample \#7).

\subsection{X-Ray diffraction testing}

Synchrotron X-ray diffraction performed in the base material and processed region of sample \#5 emphasize the existence of the $\mathrm{SiC}$ particles in the stirred zone. The strengthening precipitates typical of AA7075-T651 alloy, namely $\mathrm{Al}_{2} \mathrm{CuMg}, \mathrm{Mg}_{2} \mathrm{Si}$ and $\mathrm{MgZn}_{2}{ }^{[38]}$, were observed in both the pre- and post-processed regions, showing that the temperature reached during the process was not enough to promote their dissolution. 


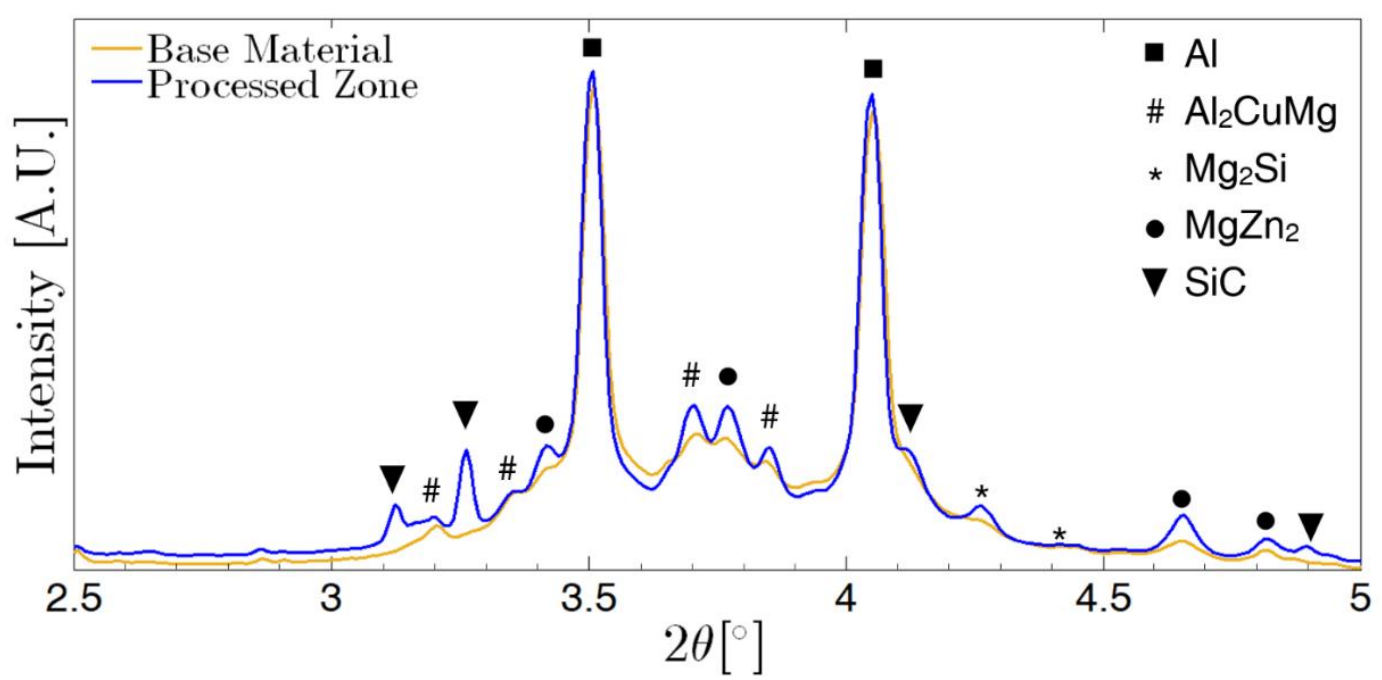

Figure 15 - Diffractogram of the composite (sample \#5) produced by UFSP using synchrotron X-ray diffraction.

\subsection{Scanning Electron Microscopy and Energy-dispersive X-ray spectroscopy}

The good performance in particles distribution shown in section 4.2, specifically the trial with 6 passes spaced by $1 \mathrm{~mm}$ in direction of the retreating side (sample \#6 - Figure 9), was analysed via SEM and EDS. Though the mechanical behaviour of the produced parts is not discussed in this paper, we show the fracture surface of sample \#6 to highlight the particle distribution induced by the novel UFSP.

Figure 16 depicts the fracture surface from tensile testing conditions of the above mentioned UFSP sample \#6 with the SiC particles, appearing in red by combination of SEM imaging and EDS analysis. The SiC particles were found piled up at the bottom of large voids (Figure 16a). At the location represented in Figure 16b, a brittle-like fracture and non-homogenous particle distribution were observed, identifying some agglomerations of SiC particles in the crack edge. Dimples with varying dimensions are identified in Figure 16c and Figure 16d, respectively. Furthermore, SiC particles were found inside the dimples, which can promote void nucleation by fracture of particles or decohesion of particle-matrix interfaces ${ }^{[39]}$. 

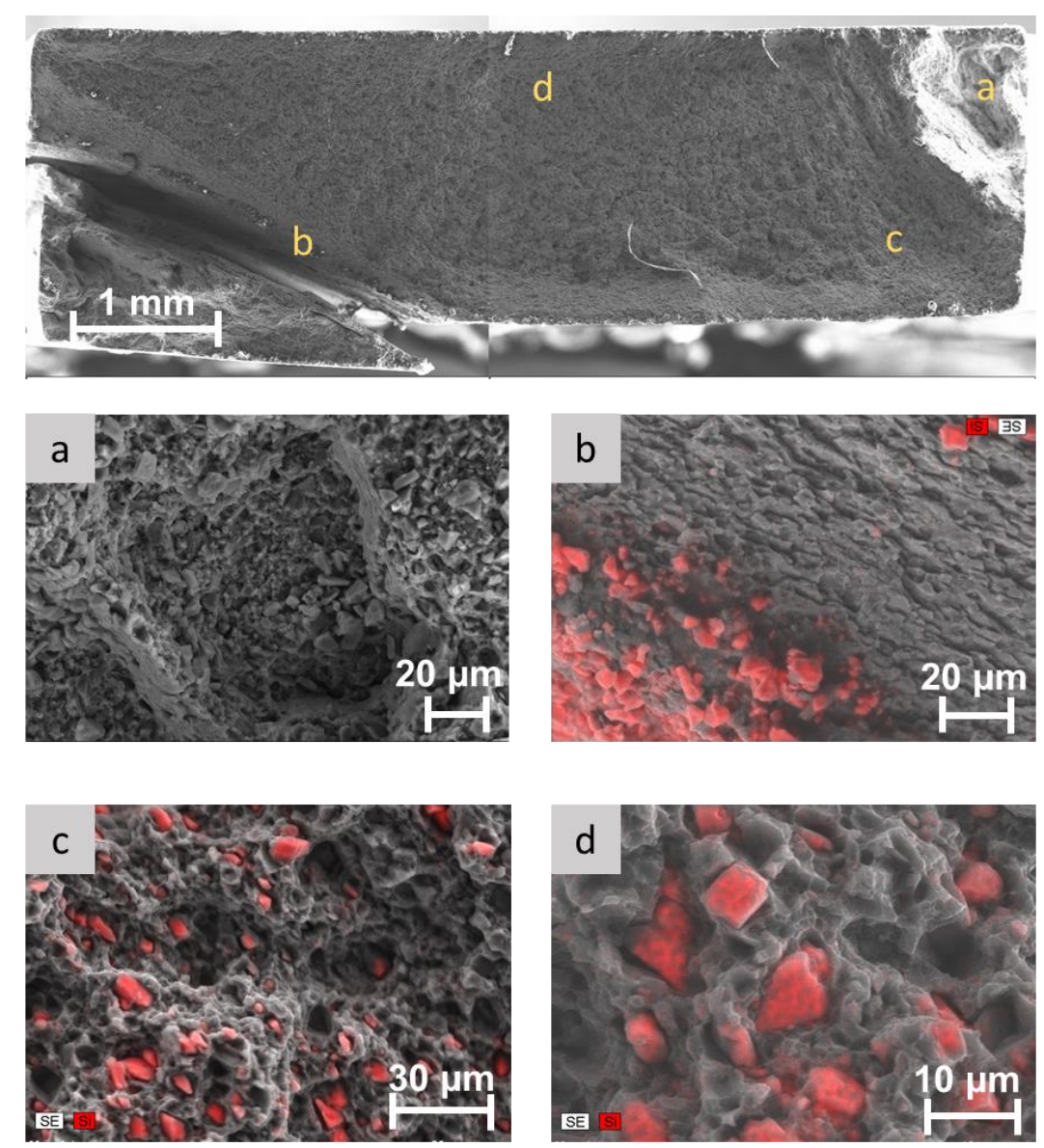

Figure 16 - SEM image of the tensile fracture surface of UFSP with 6 passes spaced by $1 \mathrm{~mm}$ in direction of retreating side with $\mathrm{SiC}$ particles.

\subsection{Electron backscatter diffraction (EBSD)}

Samples of the AA7075-T651 base material and UFSP sample \#7, without particles were analysed via EBSD. Figure 17a depicts the EBSD map of base material, in which a preferential grain orientation and texture effects can be observed, owing to previous cold rolling and artificial ageing of the aluminium alloy plate. The average grain size is approximately $31.4 \mu \mathrm{m}$.

The EBSD map of UFSP without particles is presented in Figure 17b. The original preferential grain orientation and texture effects cannot be identified anymore. No textured microstructure is present with homogenous shape and refined grains, with an average grain size reduced to about $4.0 \mu \mathrm{m}$, showing that the UFSP process promoted a full dynamic recrystallization of the stirred material. This is in agreement with results obtained previously from Gandra et al. and Suhuddin et al. ${ }^{[40,41]}$. 
The presence of the particles is clear in the EBSD map of Figure 18, for the UFSP sample \#6, with 6 passes spaced by $1 \mathrm{~mm}$ in direction of retreating side with $\mathrm{SiC}$ particles. The average grain size was of $3.9 \mu \mathrm{m}$ and most of particles were reduced to nearly 5 times of their original dimension.

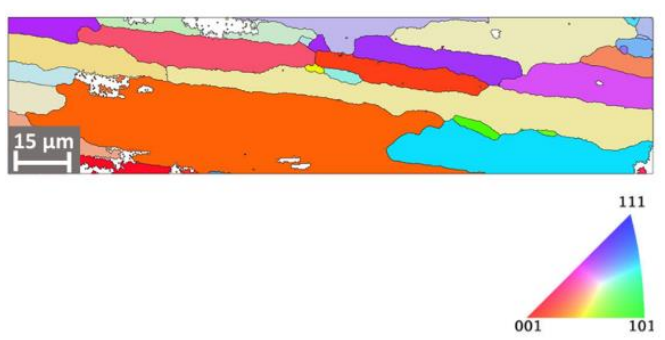

a)

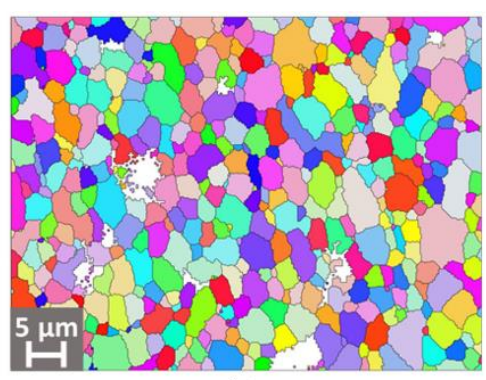

b)

Figure 17 - EBSD map: a) Base material AA7075-T651 (with IPF legend); b) UFSP with 6 passes spaced by $1 \mathrm{~mm}$ in direction of retreating side without $\mathrm{SiC}$ particles (sample 6).

a)

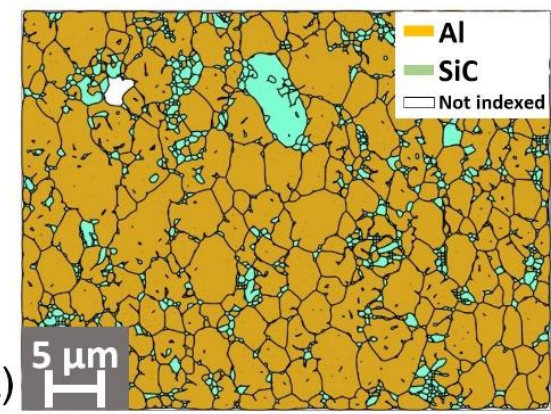

b)

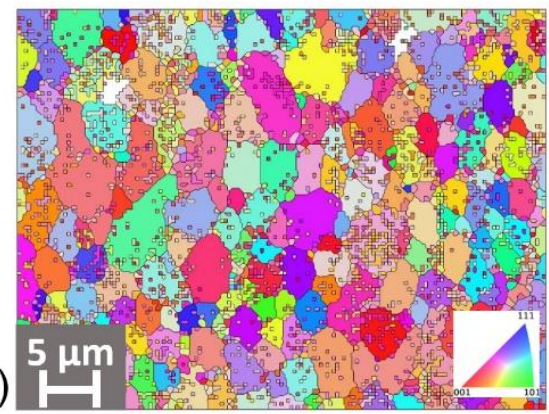

Figure 18 - EBSD map of the sample 6, UFSP sample \#6, with 6 passes spaced by $1 \mathrm{~mm}$ in direction of retreating side with SiC particles: a) Phase ID; b) Orientation map (with IPF legend).

\section{Conclusions}

An innovative variant named Upward Friction Stir Processing (UFSP) was developed and is shown to be suitable to produce customized materials with functional particles incorporated.

This UFSP variant promotes an even particle distribution throughout the processed volume after only one pass in comparison with conventional FSP since the particles are continuously confined between the two plates, instead of being compartmented in discrete holes or grooves. The admission of the particles in the nugget zone should occur from the retreating side to increase its packing density in the advancing side. The increase of the overlapping passes was not so critical for the UFSP, as the original one-pass condition was significantly uniform over 
most of the stirred zone. This outcome is of major importance in terms of productivity in manufacturing of MMCs or FGMs turning it technological and economically feasible for industrialization.

For multi-pass processing, the tool offset direction that promotes better homogeneity is from the advancing side to the retreating side. This reinforce the fact that UFSP technology is capable to promote an in-volume particle distribution.

The samples were characterized by microhardness measurements and eddy current testing, and both have shown that the material properties were significantly changed throughout the entire processed zone without fluctuations, confirming the uniform distribution of the $\mathrm{SiC}$ particles. The stirred zone by UFSP, delivered a non-textured microstructure with uniform grain structure refined from original size of about $31 \mu \mathrm{m}$ to about $4 \mu \mathrm{m}$. during the stirring effect, also the $\mathrm{SiC}$ particles were reduced to nearly 5 times of their original dimension, found as non-homogenous particle distribution, at the bottom of large voids, or finely dispersed, found inside dimples of fracture surfaces from tensile tests.

\section{Acknowledgments}

PLI would like to acknowledge Fundação para a Ciência e a Tecnologia (FCT-MCTES) for its financial support via the PhD scholarship FCT-SFRH/BD/146885/2019. PLI, CV, JPO and TGS acknowledge FCT-MCTES for its financial support via the project UID/00667/2020 (UNIDEMI).

Parts of this research were carried out at beamline P-07-HEMS at DESY, a member of the Helmholtz Association. The research leading to this result has been supported by the project CALIPSOplus under the Grant Agreement 730872 from the EU Framework Programme for Research and Innovation HORIZON 2020. 


\section{References}

[1] Rodrigues, T. A.; Duarte, V. R.; Tomás, D.; Avila, J. A.; Escobar, J. D.; Rossinyol, E.; Schell, N.; Santos, T. G.; Oliveira, J. P. In-Situ Strengthening of a High Strength Low Alloy Steel during Wire and Arc Additive Manufacturing (WAAM). Addit. Manuf., 2020, 34. https://doi.org/10.1016/j.addma.2020.101200.

[2] Song, B.; Dong, S.; Coddet, P.; Zhou, G.; Ouyang, S.; Liao, H.; Coddet, C. Microstructure and Tensile Behavior of Hybrid Nano-Micro SiC Reinforced Iron Matrix Composites Produced by Selective Laser Melting. J. Alloys Compd., 2013, 579, 415421. https://doi.org/10.1016/j.jallcom.2013.06.087.

[3] Bhadeshia, H.; Honeycombe, R. Steels: Microstructure and Properties; Elsevier, 2006. https://doi.org/10.1016/B978-0-7506-8084-4.X5000-6.

[4] Thawari, G.; Sundarararjan, G.; Joshi, S. V. Laser Surface Alloying of Medium Carbon Steel with $\mathrm{SiC}(\mathrm{P})$. Thin Solid Films, 2003, 423 (1), 41-53. https://doi.org/10.1016/S0040-6090(02)00974-4.

[5] Rana, H.; Badheka, V. Influence of Friction Stir Processing Conditions on the Manufacturing of Al-Mg-Zn-Cu Alloy/Boron Carbide Surface Composite. J. Mater. $\begin{array}{llll}\text { Process. } & \text { Technol., } & \text { 2018, }\end{array}$ https://doi.org/10.1016/j.jmatprotec.2018.01.020.

[6] Khan, M.; Rehman, A.; Aziz, T.; Shahzad, M.; Naveed, K.; Subhani, T. Effect of InterCavity Spacing in Friction Stir Processed Al 5083 Composites Containing Carbon Nanotubes and Boron Carbide Particles. J. Mater. Process. Technol., 2018, 253, 72-85. https://doi.org/10.1016/j.jmatprotec.2017.11.002.

[7] Menagen, B.; Pedahzur, R.; Avnir, D. Sustained Release from a Metal - Analgesics Entrapped within Biocidal Silver. Sci. Rep., 2017, 7 (1). https://doi.org/10.1038/s41598017-03195-w.

[8] Zhu, J.; Wei, S.; Lee, I. Y.; Park, S.; Willis, J.; Haldolaarachchige, N.; Young, D. P.; Luo, Z.; Guo, Z. Silica Stabilized Iron Particles toward Anti-Corrosion Magnetic Polyurethane Nanocomposites. RSC Adv., 2012, 2 (3), 1136-1143. https://doi.org/10.1039/c1ra00758k.

[9] Gandra, J.; Miranda, R. M.; Vilaça, P. Effect of Overlapping Direction in Multipass Friction Stir Processing. Mater. Sci. Eng. A, 2011, 528 (16-17), 5592-5599. 
https://doi.org/10.1016/j.msea.2011.03.105.

[10] Jain, V. K. S.; Yazar, K. U.; Muthukumaran, S. Development and Characterization of Al5083-CNTs/SiC Composites via Friction Stir Processing. J. Alloys Compd., 2019, 798, 82-92. https://doi.org/10.1016/j.jallcom.2019.05.232.

[11] Gandra, J.; Vigarinho, P.; Pereira, D.; Miranda, R. M.; Velhinho, A.; Vilaça, P. Wear Characterization of Functionally Graded Al-SiC Composite Coatings Produced by Friction Surfacing. Mater. Des., 2013, 52, 373-383. https://doi.org/10.1016/j.matdes.2013.05.059.

[12] Santos, T. G.; Lopes, N.; MacHado, M.; Vilaça, P.; Miranda, R. M. Surface Reinforcement of AA5083-H111 by Friction Stir Processing Assisted by Electrical Current. J. Mater. Process. Technol., 2015, 216, 375-380. https://doi.org/10.1016/j.jmatprotec.2014.10.005.

[13] Mishra, R. S.; Ma, Z. Y.; Charit, I. Friction Stir Processing: A Novel Technique for Fabrication of Surface Composite. Mater. Sci. Eng. A, 2003, 341 (1-2), 307-310. https://doi.org/10.1016/S0921-5093(02)00199-5.

[14] Rathee, S.; Maheshwari, S.; Siddiquee, A. N.; Srivastava, M. Distribution of Reinforcement Particles in Surface Composite Fabrication via Friction Stir Processing: Suitable Strategy. Mater. Manuf. Process., 2018, 33 (3), 262-269. https://doi.org/10.1080/10426914.2017.1303147.

[15] Gangil, N.; Maheshwari, S.; Siddiquee, A. N. Multipass FSP on AA6063-T6 Al: Strategy to Fabricate Surface Composites. Mater. Manuf. Process., 2018, 33 (7), 805811. https://doi.org/10.1080/10426914.2017.1415448.

[16] Abdollahzadeh, A.; Shokuhfar, A.; Cabrera, J. M.; Zhilyaev, A. P.; Omidvar, H. In-Situ Nanocomposite in Friction Stir Welding of 6061-T6 Aluminum Alloy to AZ31 Magnesium Alloy. J. Mater. Process. Technol., 2019, 263, 296-307. https://doi.org/10.1016/j.jmatprotec.2018.08.025.

[17] Lim, D. K.; Shibayanagi, T.; Gerlich, A. P. Synthesis of Multi-Walled CNT Reinforced Aluminium Alloy Composite via Friction Stir Processing. Mater. Sci. Eng. A, 2009, 507 (1-2), 194-199. https://doi.org/10.1016/j.msea.2008.11.067.

[18] Avettand-Fènoël, M. N.; Simar, A.; Shabadi, R.; Taillard, R.; de Meester, B. Characterization of Oxide Dispersion Strengthened Copper Based Materials Developed 
by Friction Stir Processing. Mater. Des., 2014, 60, 343-357. https://doi.org/10.1016/j.matdes.2014.04.012.

[19] Mertens, A.; Simar, A.; Adrien, J.; Maire, E.; Montrieux, H. M.; Delannay, F.; LecomteBeckers, J. Influence of Fibre Distribution and Grain Size on the Mechanical Behaviour of Friction Stir Processed Mg-C Composites. Mater. Charact., 2015, 107, 125-133. https://doi.org/10.1016/j.matchar.2015.07.010.

[20] Simar, A.; Mertens, A.; Ryelandt, S.; Delannay, F.; Brassart, L. Mean-Field Model Analysis of Deformation and Damage in Friction Stir Processed Mg-C Composites. Mater. Sci. Eng. A, 2018, 723, 324-333. https://doi.org/10.1016/j.msea.2018.03.043.

[21] Ni, D. R.; Wang, J. J.; Zhou, Z. N.; Ma, Z. Y. Fabrication and Mechanical Properties of Bulk NiTip/Al Composites Prepared by Friction Stir Processing. J. Alloys Compd., 2014, 586, 368-374. https://doi.org/10.1016/j.jallcom.2013.10.013.

[22] Netto, N.; Zhao, L.; Soete, J.; Pyka, G.; Simar, A. Manufacturing High Strength Aminum Matrix Composites by Friction Stir Processing: An Innovative Approach. $J$. $\begin{array}{lllll}\text { Mater. } & \text { Process. } & \text { Technol., } & \mathbf{2 0 2 0}, & 283,\end{array}$ https://doi.org/10.1016/J.JMATPROTEC.2020.116722.

[23] Guo, J. F.; Liu, J.; Sun, C. N.; Maleksaeedi, S.; Bi, G.; Tan, M. J.; Wei, J. Effects of Nano-A12O3 Particle Addition on Grain Structure Evolution and Mechanical Behaviour of Friction-Stir-Processed Al. Mater. Sci. Eng. A, 2014, 602, 143-149. https://doi.org/10.1016/j.msea.2014.02.022.

[24] Yuvaraj, N.; Aravindan, S.; Vipin. Fabrication of A15083/B4C Surface Composite by Friction Stir Processing and Its Tribological Characterization. J. Mater. Res. Technol., 2015, 4 (4), 398-410. https://doi.org/10.1016/J.JMRT.2015.02.006.

[25] Nascimento, F.; Santos, T.; Vilaça, P.; Miranda, R. M.; Quintino, L. Microstructural Modification and Ductility Enhancement of Surfaces Modified by FSP in Aluminium Alloys. Mater. Sci. Eng. A, 2009, $506 \quad$ (1-2), 16-22. https://doi.org/10.1016/j.msea.2009.01.008.

[26] Gandra, J.; Miranda, R.; Vilaa, P.; Velhinho, A.; Teixeira, J. P. Functionally Graded Materials Produced by Friction Stir Processing. J. Mater. Process. Technol., 2011, 211 (11), 1659-1668. https://doi.org/10.1016/j.jmatprotec.2011.04.016.

[27] Sharma, V.; Prakash, U.; Kumar, B. V. M. Surface Composites by Friction Stir 
Processing: A Review. J. Mater. Process. Technol., 2015, 224, 117-134. https://doi.org/10.1016/j.jmatprotec.2015.04.019.

[28] Sorger, G. L.; Oliveira, J. P.; Inácio, P. L.; Enzinger, N.; Vilaça, P.; Miranda, R. M.; Santos, T. G. Non-Destructive Microstructural Analysis by Electrical Conductivity: Comparison with Hardness Measurements in Different Materials. J. Mater. Sci. Technol., 2019, 35 (3), 360-368. https://doi.org/10.1016/j.jmst.2018.09.047.

[29] Santos, T. G.; Miranda, R. M.; Vilaça, P.; Teixeira, J. P.; dos Santos, J. Microstructural Mapping of Friction Stir Welded AA 7075-T6 and AlMgSc Alloys Using Electrical Conductivity. Sci. Technol. Weld. Join., 2011, 16 (7), 630-635. https://doi.org/10.1179/1362171811Y.0000000052.

[30] Hammersley, A. P.; Svensson, S. O.; Hanfland, M.; Fitch, A. N.; Häusermann, D. TwoDimensional Detector Software: From Real Detector to Idealised Image or Two-Theta Scan. High Press. Res., 1996, $14 \quad$ (4-5), 235-248. https://doi.org/10.1080/08957959608201408.

[31] Oliveira, J. P.; Braz Fernandes, F. M.; Miranda, R. M.; Schell, N. On the Mechanisms for Martensite Formation in YAG Laser Welded Austenitic NiTi. Shape Mem. Superelasticity, 2016, 2 (1), 114-120. https://doi.org/10.1007/s40830-016-0058-z.

[32] Reynolds, A. P. Visualisation of Material Flow in Autogenous Friction Stir Welds. Sci. Technol. Weld. $\quad$ Join., $2000, \quad 5 \quad$ (2), 120-124. https://doi.org/10.1179/136217100101538119.

[33] Dialami, N.; Cervera, M.; Chiumenti, M. Defect Formation and Material Flow in Friction Stir Welding. Eur. J. Mech. A/Solids, 2020, 80 (May 2019), 103912. https://doi.org/10.1016/j.euromechsol.2019.103912.

[34] Pashazadeh, H.; Masoumi, A.; Teimournezhad, J. A Study on Material Flow Pattern in Friction Stir Welding Using Finite Element Method. Proc. Inst. Mech. Eng. Part B J. Eng. Manuf., 2013, 227 (10), 1453-1466. https://doi.org/10.1177/0954405413485952.

[35] Vidal, C.; Infante, V.; Vilaça, P. Metallographic and Morphological Characterization of Sub-Surface Friction Stirred Channels Produced on AA5083-H111. Int. J. Adv. Manuf. Technol., 2019, 105 (5-6), 2215-2235. https://doi.org/10.1007/s00170-019-04459-7.

[36] Machado, M. A.; Rosado, L.; Pedrosa, N.; Vostner, A.; Miranda, R. M.; Piedade, M.; Santos, T. G. Novel Eddy Current Probes for Pipes: Application in Austenitic Round- 
in-Square Profiles of ITER. NDT E Int., 2017, 87, 111-118. https://doi.org/10.1016/j.ndteint.2017.02.001.

[37] Santos, T.; Vilaça, P.; Quintino, L. Developments in NDT for Detecting Imperfections in Friction Stir Welds in Aluminium Alloys. Weld. World, 2008, 52 (9-10), 30-37. https://doi.org/10.1007/BF03266666.

[38] Birbilis, N.; Cavanaugh, M. K.; Buchheit, R. G. Electrochemical Behavior and Localized Corrosion Associated with A17Cu2Fe Particles in Aluminum Alloy 7075$\begin{array}{lllll}\text { T651. Corros. } & \text { Sci., } & \text { 2006, } & 48 & \text { (12), }\end{array}$ https://doi.org/10.1016/j.corsci.2006.02.007.

[39] Lynch, S. P. Metallographic and Fractographic Techniques for Characterising and Understanding Hydrogen-Assisted Cracking of Metals. Gaseous Hydrog. Embrittlement Mater. Energy Technol., 2012, 274-346. https://doi.org/10.1533/9780857093899.2.274.

[40] Gandra, J.; Pereira, D.; Miranda, R. M.; Silva, R. J. C.; Vilaça, P. Deposition of AA6082-T6 over AA2024-T3 by Friction Surfacing - Mechanical and Wear Characterization. Surf. Coatings Technol., 2013, 223, 32-40. https://doi.org/10.1016/j.surfcoat.2013.02.023.

[41] Suhuddin, U.; Mironov, S.; Krohn, H.; Beyer, M.; Dos Santos, J. F. Microstructural Evolution during Friction Surfacing of Dissimilar Aluminum Alloys. Metall. Mater. Trans. A Phys. Metall. Mater. Sci., 2012, 43 (13), 5224-5231. https://doi.org/10.1007/s11661-012-1345-8. 